\title{
Life on the rocks: Multilocus phylogeography of rock hyrax (Procavia capensis) from southern Africa
}

K. Amanda Maswanganye ${ }^{\mathrm{a}, \mathrm{b}^{*}}$, Michael J. Cunningham ${ }^{\mathrm{b}}$, Nigel C. Bennett ${ }^{\mathrm{a}}$, Christian T. Chimimba ${ }^{\text {a }}$, Paulette Bloomer ${ }^{\text {b* }}$

${ }^{a}$ Department of Zoology and Entomology, University of Pretoria, Private Bag X20, Hatfield, 0028, South Africa; amaswang@zoology.up.ac.za; ncbennett@zoology.up.ac.za; ctchimimba@zoology.up.ac.za

${ }^{\mathrm{b}}$ Molecular Ecology and Evolution Programme, Department of Genetics, University of Pretoria, Private Bag X20, Hatfield, 0028, South Africa; Michael.cunningham@up.ac.za; paulette.bloomer@up.ac.za

* Corresponding authors: K. Amanda Maswanganye and Paulette Bloomer, Department of Genetics, Room 7-34 Agricultural Sciences Building, cnr Lynnwood and University Roads, University of Pretoria, Hatfield, 0028, South Africa

E-mail address: amaswang@zoology.up.ac.za; paulette.bloomer@up.ac.za

\section{Highlights}

- Deep mitochondrial lineages in the rock hyrax from southern Africa.

- Divergence between lineages dates to the Miocene.

- The multi-locus data fit a model of isolation with migration.

- The species distribution and diversification is affected by habitat dependence and climate changes.

\section{Graphical abstract}
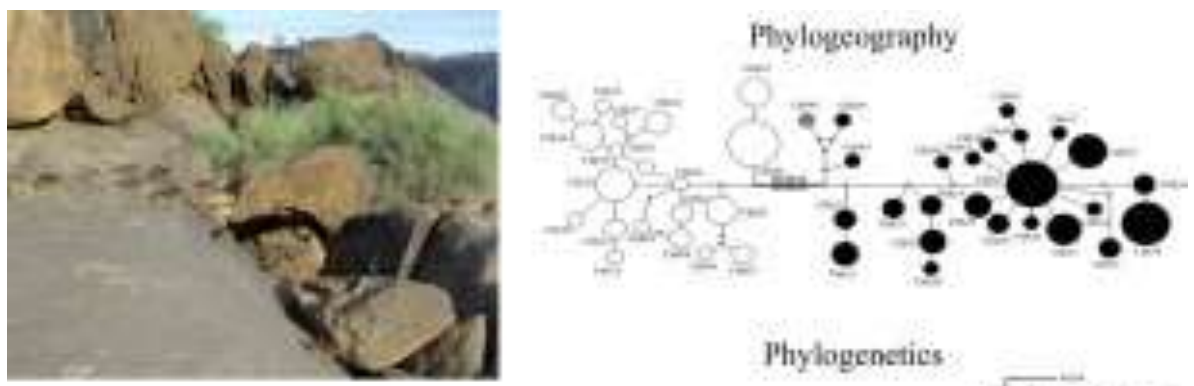

Distribution moddling
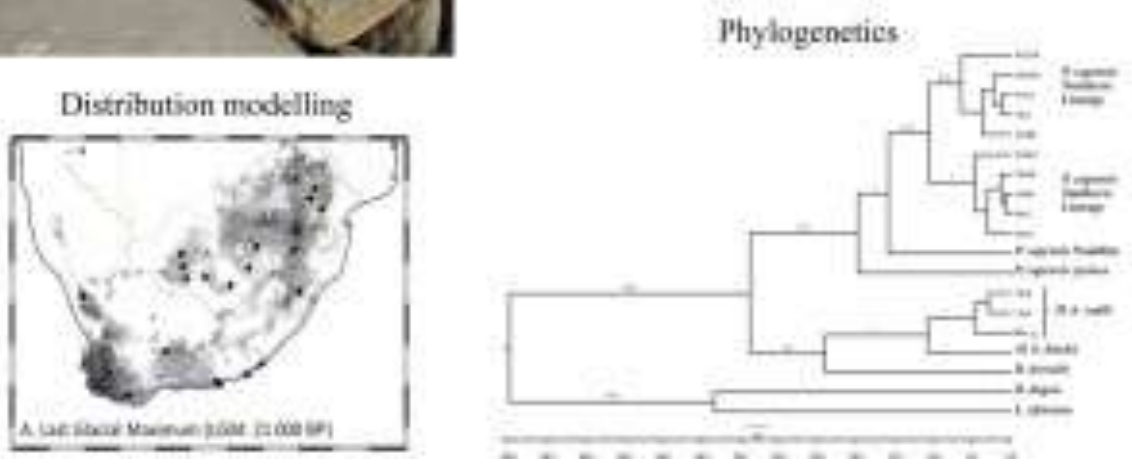


\section{A B S T R A C T}

Understanding the role of geography and climatic cycles in determining patterns of biodiversity is important in comparative and evolutionary biology and conservation. We studied the phylogeographic pattern and historical demography of a rock-dwelling small mammal species from southern Africa, the rock hyrax Procavia capensis. Using a multilocus coalescent approach, we assessed the influence of strong habitat dependence and fluctuating regional climates on genetic diversity. We sequenced a mitochondrial gene (cytochrome $b$ ) and two nuclear introns (AP5, PRKC1) supplemented with microsatellite genotyping, in order to assess evolutionary processes over multiple temporal scales. In addition, distribution modelling was used to investigate the current and predicted distribution of the species under different climatic scenarios. Collectively, the data reveal a complex history of isolation followed by secondary contact shaping the current intraspecific diversity. The cyt $b$ sequences confirmed the presence of two previously proposed geographically and genetically distinct lineages distributed across the southern African Great Escarpment and north-western mountain ranges. Molecular dating suggests Miocene divergence of the lineages, yet there are no discernible extrinsic barriers to gene flow. The nuclear markers reveal incomplete lineage sorting or ongoing mixing of the two lineages. Although the microsatellite data lend some support to the presence of two subpopulations, there is weak structuring within and between lineages. These data indicate the presence of gene flow from the northern into the southern parts of the southern African sub-region likely following the secondary contact. The distribution modelling predictably reveal the species' preference for rocky areas, with stable refugia through time in the northern mountain ranges, the Great Escarpment, as well as restricted areas of the Northern Cape Province and the Cape Fold Mountains of South Africa. Different microclimatic variables appear to determine the distributional range of the species. Despite strong habitat preference, the micro-habitat offered by rocky crevices and unique life history traits likely promoted the adaptability of $P$. capensis, resulting in the widespread distribution and persistence of the species over a long evolutionary period. Spatio-temporal comparison of the evolutionary histories of other co-distributed species across the rocky landscapes of southern Africa will improve our understanding of the regional patterns of biodiversity and local endemism. 
Keywords: Afrotheria; coalescence; distribution modeling; isolation-with-migration; saxicolous mammal; vicariance

\section{Introduction}

Southern Africa is exceptionally rich in rocky landscapes varying from wet temperate and tropical mountain peaks, to dolerite buttes, known as kopjes or koppies of the arid inland plateau. Around the edge of this plateau runs the Great Escarpment, a ribbon-like erosional remnant of Jurassic subcontinent-wide lava flows and Gondwanic rifting with subsequent uplift and warping (Ollier and Pain, 2000; McCarthy and Rubidge, 2005; Partridge et al., 2006;). These landscapes are also geologically diverse encompassing highly metamorphosed Archaean basements, over 3.5 billion years old in the north, through to recently exposed Pleistocene limestone and conglomerate along the southern coast (McCarthy and Rubidge, 2005; Johnson et al., 2006). Several saxicolous animal species are distributed across the region.

Whereas rocky habitats may act as barriers to gene flow in some species (Körner, 2004; Kok et al., 2012), for others they represent areas of long term stability (Kingdon, 1990), with low "change velocity" (Smethurst, 2000; Sandel et al., 2011). Environmental heterogeneity in mountains and other rocky areas provide micro-habitats with lesser extremes of temperature and humidity than the surrounds and therefore offer a relatively stable food supply and a variety of shelters (Spehn et al., 2011; Kingdon et al., 2013). This refugial effect may allow isolated populations to survive for long periods in areas of otherwise unsuitable climate and may buffer interconnected populations in the face of adverse climatic change.

The rock hyrax or dassie (Procavia capensis) is among the most familiar animals in southern African rocky habitats. This widespread small mammal species from an Oligocene Afrotherian lineage (Springer et al., 2003; Gheerbrant et al., 2007; Seiffert, 2007), is adapted to rocky crevices, krantzes and koppies. Currently a single species of rock hyrax is recognised throughout its African and Arabian distribution, however, numerous poorly defined species or subspecies have been described mainly based on minor variations in pelage colour. Many authors have proposed that a taxonomic revision is warranted (Allen, 1939; Ellerman and Morrison-Scott, 1953; Bothma, 1971; 
Meester et al., 1986; Barry and Shoshani, 2000) and it is likely that cryptic diversity exists, although the boundaries between forms remain unclear.

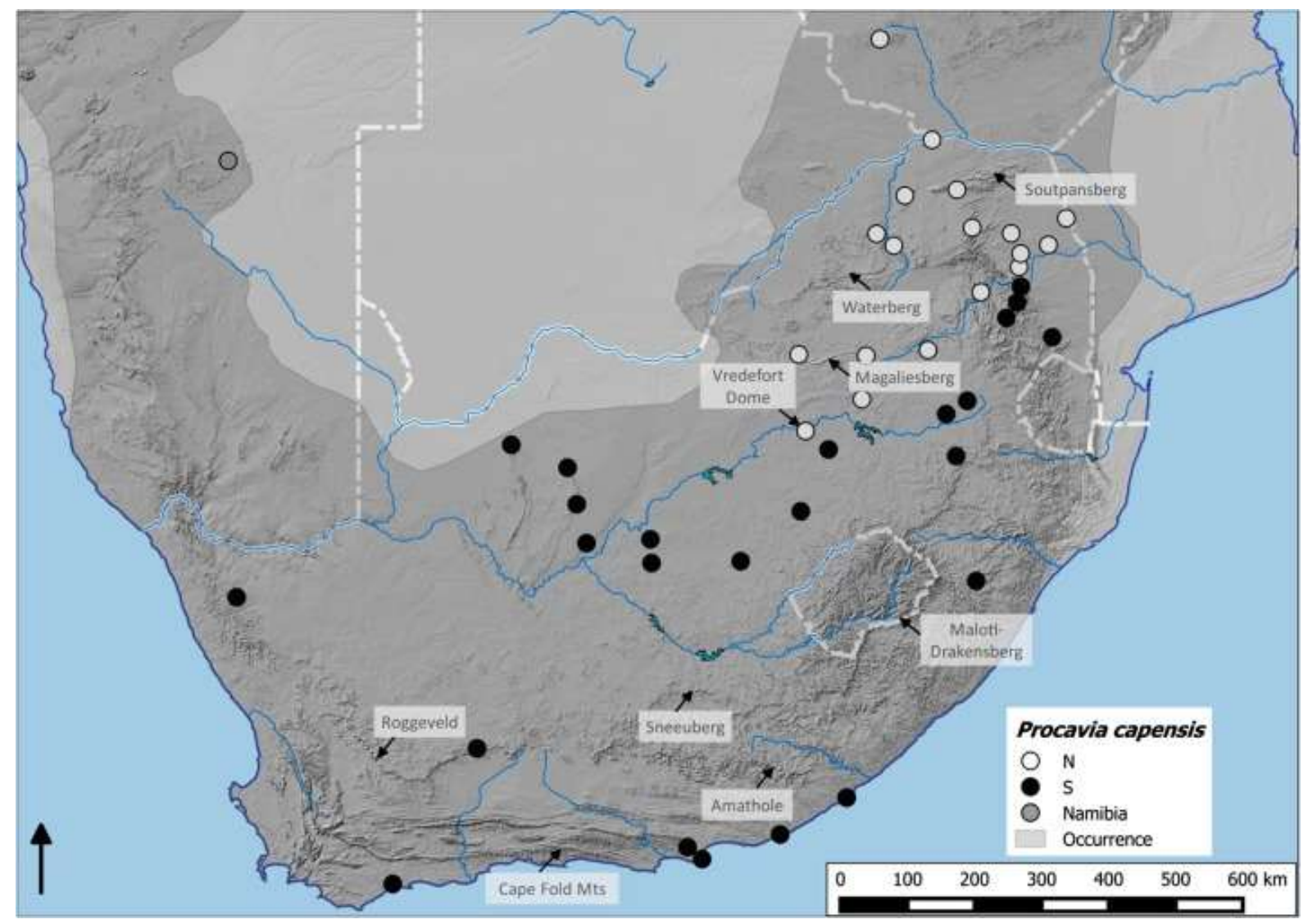

Fig. 1. Sampling localities of Procavia capensis capensis from southern Africa. The localities are colour coded to correspond with northern (white), southern (black) and Namibian (grey) lineages recovered in the mtDNA haplotype network.

Rock hyrax occur extensively throughout much of southern Africa from the south-western Cape to the northern borders of South Africa and into Zimbabwe and Namibia, being absent only from the Kalahari sands in the interior, and the Mozambique-Maputaland coastal plain in the northeast (Fig. 1; Supplementary Fig. S1). A previous phylogeographic study found mitochondrial DNA (mtDNA) evidence of two distinct lineages (Prinsloo and Robinson, 1992), one distributed along the southern and eastern sections of the Great Escarpment and the other across several mountain ranges in the northern parts of South Africa extending to the Matopo Hills of Zimbabwe (Prinsloo, 1993). Whereas the Great Escarpment represents fairly continuous habitat availability for hyrax occupation, the northern mountain ranges are more isolated. The species is also recorded from smaller rocky outcrops surrounded by what would appear to be uninhabitable plains that lack crevices and pose high risks of 
predation. Rock hyrax population numbers fluctuate within sites and regionally in response to drought, food availability and possibly, disease, with large-scale population irruptions leading to colonization of marginal habitats (van der Horst, 1941; Lensing, 1979). Similar population dynamics occur in the congeneric P. c. johnstoni from Serengeti National Park in Tanzania which displays characteristic metapopulation structure where habitat patches experience recurrent cycles of extinction and recolonization (Grant and Leslie, 1992; Gerlach and Hoeck, 2001). These populations are also characterized by low genetic variability, a high degree of inbreeding and contrary to most mammals, P. c. johnstoni does not display sex biased dispersal (Gerlach and Hoeck, 2001).

The rock hyrax shows several life-history traits that may impact on genetic diversity across the species range. Rock hyraxes are thermo-labile, strongly affecting their diurnal activity patterns, dependence on rock crevices for shelter, and gregarious nature (Skinner and Chimimba, 2005; Kingdon et al., 2013). Multiple groups can be found co-inhabiting a network of rocky outcrops, with the dominant and often territorial male monopolizing several matrilineal groups. Within this social system the immature males are usually the dispersers, while the females tend to be philopatric (Coe, 1962; Fourie and Perrin, 1987; Hoeck et al., 1982; Hoeck, 1989). Procavia capensis is a grazer, but will switch to browsing when food is not abundant (Sale, 1965, 1966; Turner and Watson, 1965; Hoeck, 1975; Fourie, 1983). These traits would influence abundance and patchiness of rock hyrax occurrence. In the northern parts of southern Africa they occur in sympatry with Heterohyrax brucei (bush hyrax or yellow-spotted hyrax) that is more narrowly distributed, potentially due to its more restricted diet (mostly browsing).

Studies of other saxicolous fauna in southern Africa have reported similar patterns of occurrence and phylogeographic structure. For example, deep genetic disjunctions between mitochondrial lineages in Smith's red rock rabbit (Pronolagus rupestris; Matthee and Robinson, 1996), southern rock agama (Agama atra; Matthee and Flemming, 2002), Cape rock elephant shrew (Elephantulus edwardii; Smit et al., 2007), and flat geckos (Afroedura spp., Makhubo et al., 2014). These breaks broadly correspond across species, emphasizing the Drakensberg Highlands, Great Escarpment, Cape Fold Mountains and north-western mountain ranges as dominant features of the southern African 
landscape. However, there are also species-specific patterns and ecologically determined differences in species responses to climate variation across patchy habitats.

Palaeoclimatic change is the major driver invoked in environmental adaptation and phylogeographic structuring of species (Avise, 2000; Hewitt, 2000, 2011; Waltari et al., 2007). Repeated climatic fluctuations and aridification caused by Pleistocene global glacial cycles have caused periodic habitat fragmentation, resulting in isolation, extirpation or diversification (Linder, 2003; Hewitt, 2004; Chase and Meadows, 2007; Cowling et al., 2009). The patchy distribution of suitable outcrops and stability of this habitat may give rise to isolated refugial populations and the formation of new lineages over time. This, together with the variability of hyrax recruitment and mortality must drastically alter population composition in response to climatic change. An approach that combines comparative phylogeography and bioclimatic distribution modelling projected onto past climatic scenarios, may allow us to trace the chronology of events leading to lineage divergence (Schneider et al., 1998; Waltari et al., 2007; Carnaval et al., 2009; Svenning et al., 2011).

Intuitively one might expect patchily distributed rock-dwelling species to be characterized by strong genetic partitioning. However, different markers may vary in sensitivity to genetic structure, across spatial and temporal scales due to varying effective population size, mutation rates, gene migration and homoplasy. Among mammals, mtDNA is frequently used to test hypotheses of relationships among closely related taxa and intraspecific phylogeography (Prager et al., 1996; Taberlet et al., 1998; Hewitt, 2011; Fordham et al., 2014). Introns provide an ideal source of nuclear noncoding sequences especially where they are anchored in conserved exons allowing robust PCR primer design (Pamilo and Nei, 1988; Hudson and Coyne, 2002; Hare and Palumbi, 2003). The high mutation rates of microsatellites offer a more recent perspective, with better resolution of variation within populations, extending insights to ecological time scales (Ashley and Dow, 1994; Schlötterer and Pemberton, 1994).

Here we present a multi-locus phylogeographic assessment of rock hyrax within a coalescent framework. The main questions addressed are: (a) What are the major evolutionary lineages as defined through analyses of different marker systems?; (b) What are the broader relationships and timing of diversification among southern African lineages?; (c) Is there evidence of recent gene flow 
and population structure within and between the identified lineages?; and (d) how does climate change affect population connectivity of rock hyrax across southern Africa?

\section{Materials and methods}

\subsection{Sample collection and laboratory protocols}

Specimens of $P$. capensis capensis were collected by multiple contributors from geographic localities across southern Africa (Fig. 1; Supplementary Table S1). Heart, liver and muscle tissue were dissected from a limited number of individuals and frozen at $-20^{\circ} \mathrm{C}$, with voucher specimens registered at Ditsong Museum, Pretoria, South Africa. In total a combination of 125 samples were used in the final molecular analyses depending on PCR and genotyping success. The final counts were 110 individuals for mtDNA sequencing, 30-50 for intron sequencing and 104 for microsatellite genotyping. Additional presence locality data were obtained from the MammalMAP database (mammalmap.adu.org.za) with permission from data providers at the National Museum, Bloemfontein and the MacGregor Museum, Kimberley, South Africa.

Total genomic DNA was extracted from $20 \mathrm{mg}$ of preserved tissue using the Sigma GenElute ${ }^{\mathrm{TM}}$ Mammalian Genomic DNA Miniprep kit (Sigma Aldrich) or Qiagen DNeasy Blood and Tissue extraction kit (Qiagen), following the manufacturer's instructions. Extracted DNA pellets were airdried and re-suspended in 50-100 $\mu \mathrm{l} \mathrm{Sabax}{ }^{\circledR}$ water (Adcock Ingram), and stored at $4{ }^{\circ} \mathrm{C}$. DNA quality and concentration was assessed from gel electrophoresis and a NanoDrop fluorospectrometer (Thermo Fisher Scientific). Oligonucleotide primers (Supplementary Table S2), obtained by redesigning universal primers of Irwin et al. (1991), were used to amplify the mtDNA cytochrome $b$ (cyt $b$ ) gene. Due to difficulties with amplification or sequencing in some samples, the final analyses were based on a 786 bp alignment. All polymerase chain reactions (PCR) were performed in a total volume of $25 \mu \mathrm{l}$ containing $20-100 \mathrm{ng}$ genomic DNA, $1 \mathrm{X}$ reaction buffer, $2-2.5 \mathrm{mM} \mathrm{MgCl}_{2}, 0.3-0.5$ $\mathrm{mM}$ dNTPs, 2.5-5 pmol of each primer, and 1 U Supertherm Taq polymerase (Southern Cross Biotechnologies). PCR reactions were performed using the GeneAmp 2720 thermal cycler (Applied 
Biosystems). Amplification was performed in 35 cycles, each cycle comprising: 30 s denaturation at $94{ }^{\circ} \mathrm{C}, 30 \mathrm{~s}$ annealing at $52{ }^{\circ} \mathrm{C}$ and $45 \mathrm{~s}$ extension at $72{ }^{\circ} \mathrm{C}$, with the final extension for $10 \mathrm{~min}$ at 72

${ }^{\circ} \mathrm{C}$. The presence of successful PCR products were confirmed on $2 \%$ agarose gels stained with GelRed $^{\mathrm{TM}}$ Acid stain (Biotium).

In order to obtain resolution across multiple temporal scales we analysed a representative subset of samples selected from across the mtDNA cyt $b$ gene tree and the geographic sampling, for two nuclear introns: AP5, PRKC1 (Acid phosphatase type V intron 2 and Protein kinase C iota, respectively) (Supplementary Table S2). The PCR profiles for AP5 and PRKC1 were $94{ }^{\circ} \mathrm{C}$ for $2 \mathrm{~min}$, followed by $94{ }^{\circ} \mathrm{C}$ for $30 \mathrm{~s}, 52{ }^{\circ} \mathrm{C}, 56{ }^{\circ} \mathrm{C} / 52{ }^{\circ} \mathrm{C}$, respectively for $1 \min 30 \mathrm{~s}, 72^{\circ} \mathrm{C}$ for $1 \mathrm{~min}$, repeated for 35 cycles, followed by a final extension of $72{ }^{\circ} \mathrm{C}$ for $10 \mathrm{~min}$. The numbers of samples and fragment sizes utilized are summarised in Table 1.

Sequencing amplicons were purified using either the High Pure PCR Product or the ExoSap purification kit (Roche Diagnostics; Affymatrix). Purified PCR products were then sequenced in both directions using BigDye ${ }^{\mathrm{TM}}$ Terminator 3.1 cycle sequencing ready reaction kit (Applied Biosystems) according to the manufacturer's protocol. Cycle sequenced products were precipitated using $3 \mathrm{M}$ NaAc (sodium acetate) (Applied Biosystems) and separated on ABI PRISM 3130/3730 Genetic DNA Analysers (Applied Biosystems). The electropherograms were visually explored, trimmed, aligned with Clustal X and checked for peptide translation in MEGA 6 (Thompson et al., 1997; Tamura et al., 2013), and consensus sequences annotated in CLC Main Workbench5/6 (CLC Bio). Sequences were later deposited in GenBank (Supplementary Table S4).

Microsatellite genotyping utilized previously published markers from Gerlach et al., (2000) and Koren and Geffen (2011) (Supplementary Table S3). A hundred and four samples were genotyped, with 24 of these randomly chosen for re-genotyping to assess genotyping error. PCR reactions were prepared in $10 \mu \mathrm{l}$ volumes with approximately $50 \mathrm{ng}$ of genomic DNA, 1x PCR buffer, $0.3 \mathrm{U}$ Supertherm Taq polymerase, $1.5-2.5 \mathrm{mM} \mathrm{MgCl}_{2}, 1 \mathrm{pmol}$ of the forward and reverse primers (Inqaba Biotec), $0.2 \mathrm{mM}$ dNTPs (Promega) and 0.02 pmol fluorescently labelled ChromaTideRhodamine Green $^{\mathrm{TM}}$-5-dUTPs (Invitrogen). PCR conditions for each locus are given in Supplementary Table S3. 


\section{Table 1}

Summary statistics for the three sequenced gene regions, including number of individual $(N)$ in mtDNA defined population groups, number of haplotypes/alleles within groups $(H)$, variable sites, parsimony informative sites, haplotype/allelic diversity $\left(H_{\mathrm{d}}\right)$, nucleotide diversity $(\pi)$ and their standard deviations, mutational parameters $\theta \mathrm{s}$ (Watterson 1975) and $\theta \pi$ (Tajima 1983), Tajima's $D$ test statistic and Fu's $F$ s. Significance level: NS $=P>0.05, * P<0.05, * * P<0.01, * * * P<0.001$.

\begin{tabular}{|c|c|c|c|c|c|c|c|c|c|c|c|c|}
\hline \multirow[t]{4}{*}{ Locus } & \multirow[t]{4}{*}{ Clade } & \multirow{4}{*}{$\begin{array}{l}\text { Length } \\
\text { (bp) }\end{array}$} & \multicolumn{10}{|c|}{ Polymorphism } \\
\hline & & & $N$ & $H$ & Variable & Parsimony & $H_{\mathrm{d}}( \pm \mathrm{SD})$ & $\pi( \pm \mathrm{SD})$ & $\theta \mathrm{s}( \pm \mathrm{SD})$ & $\theta \pi( \pm \mathrm{SD})$ & Tajima's $D$ & Fu's $F \mathrm{~s}$ \\
\hline & & & & & sites & informative & & & & & & \\
\hline & & & & & & sites & & & & & & \\
\hline \multirow[t]{3}{*}{ Cyt $b$} & All & 786 & 110 & 45 & 125 & 78 & - & - & - & - & - & - \\
\hline & Northern group & & 49 & 20 & - & - & $0.93( \pm 0.01)$ & $0.02( \pm 0.009)$ & $7( \pm 2)$ & $7( \pm 2)$ & -0.19 & -2.71 \\
\hline & Southern group & & 61 & 25 & - & - & $0.93( \pm 0.02)$ & $0.07( \pm 0.001)$ & $10( \pm 2)$ & $6( \pm 2)$ & $-2.26^{* *}$ & -3.69 \\
\hline \multirow[t]{3}{*}{ AP5 } & All & 304 & 46 & 15 & 27 & 4 & - & - & - & & & \\
\hline & Northern group & & 25 & 13 & - & - & $0.78( \pm 0.09)$ & $0.01( \pm 0.004)$ & $10( \pm 3)$ & $4( \pm 2)$ & $-2.28 * *$ & -3.75 \\
\hline & Southern group & & 21 & 8 & - & - & $0.57( \pm 0.13)$ & $0.01( \pm 0.005)$ & $7( \pm 2)$ & $2( \pm 1)$ & $-2.46^{* * *}$ & -1.49 \\
\hline \multirow[t]{3}{*}{ PRKC1 } & All & 419 & 30 & 21 & 43 & 7 & - & - & - & - & - & - \\
\hline & Northern group & & 12 & 11 & - & - & $0.99( \pm 0.04)$ & $0.02( \pm 0.004)$ & $7( \pm 2)$ & $4( \pm 2)$ & $-1.79 *$ & -6.44 \\
\hline & Southern group & & 18 & 9 & - & - & $0.84( \pm 0.07)$ & $0.02( \pm 0.007)$ & $9( \pm 3)$ & $6( \pm 2)$ & -1.59 & 0.06 \\
\hline
\end{tabular}

(-) Represents values that were not estimated 
After confirming amplification on 2\% agarose gels, fragment size and polymorphism was assessed on an ABI 3500xl Genetic Analyzer (Applied Biosystems). The forward primer of each selected polymorphic microsatellite locus was subsequently fluorescently labelled with the G5 dye set (Supplementary Table S3) (Applied Biosystems). These were then co-loaded and analysed on an ABI 3500xl, with the GeneScan Liz ${ }^{\mathrm{TM}} 500$ Size Standard (Applied Biosystems).

\subsection{Estimation of molecular diversity from sequence data}

For both the mtDNA (cyt $b$ ) and nuclear intronic regions (AP5, PRKC1) Arlequin 3.5 (Excoffier and Lischer, 2010) and DNASP 5.10.01 (Librado and Rozas, 2009) were used to compute standard diversity statistics, including number of haplotypes $(h)$, haplotype diversity $(H)$, segregating sites $(s)$, and nucleotide diversity $(\pi)$ per site $(\mathrm{Nei}, 1987)$. We also calculated two estimators of the mutational parameter $\theta$ s (Watterson, 1975) and $\theta \pi$ (Tajima, 1983) along with Tajima's $D$ (Tajima, 1983) and Fu's Fs (Fu, 1997), which are indicators of either selection or demographic change. Pairwise genetic distances ( $p$-distance) were calculated for each locus in MEGA 6 (Nei and Kumar, 2000; Tamura et al., 2013).

\subsection{Gene-tree based population and demographic analyses}

Median-joining (MJ) networks (Bandelt et al., 1999) were inferred using NETWORK 4.1.0.1 (available at http://www.fluxus-technology.com/sharenet.htm; Bandelt et al., 1999). Habitat expansion and/or contraction usually imply episodes of population growth and decline, which leave characteristic signals in molecular data (Rogers and Harpending, 1992). The observed distribution of pairwise differences (mismatch distribution) was compared with that expected under sudden demographic expansion (Excoffier and Lischer, 2010) and spatial expansion (Schneider and Excoffier, 1999) models assuming constant deme sizes as implemented in Arlequin 3.5 (Excoffier and Lischer, 2010). The expansion null hypothesis was tested using the sum of squared deviation (SSD; Schneider and Excoffier, 1999) and the raggedness index (RI, Harpending, 1994). The fit of the observed distribution to both models of expansion was tested using 10,000 permutations. 
Evidence of historical demographic changes through time in the rock hyrax was further investigated using Bayesian skyline plots (BSP), a coalescent-based approach implemented in BEAST 1.6.1 (Drummond and Rambaut, 2007a, b). The program was initially run without constraints and then with a set mtDNA mutation rate estimated from previous publications on hyrax (Springer, et al., 1997, 1999, 2011; Benton and Donoghue, 2007). Input files were created in BEAUTi with appropriate parameters and mutation rate (section 2.6). Linear and stepwise models for each population used a strict clock or an uncorrelated lognormal relaxed clock were applied, with runs consisting of $5 \times 10^{6}$ generations, sampled every $1000^{\text {th }}$ generation and with the first $25 \%$ of samples excluded as burn-in. All analyses were examined for convergence using Tracer 1.5.0 (Rambaut and Drummond, 2009) with the effective sample size (ESS) used to evaluate convergence among chains.

\subsection{Microsatellite genotyping and analyses}

Genotypes were scored using GENEMARKER 1.5 (SoftGenetics). MICRO-CHECKER 2.2.3 (Van Oosterhout et al., 2004) was used to test for the presence of null alleles, large allele dropouts and scoring errors because of stutter peaks. These genotyping errors can cause deviations from HardyWeinberg proportions, in particular heterozygote deficiency (Rousset and Raymond, 1995) which can potentially bias population genetic analyses. Deviations from Hardy-Weinberg Equilibrium and linkage disequilibrium between individuals and markers were tested with GENEPOP 4.0.10 (Rousset, 2008), using 10,000 steps and 10,000 iterations. Summary statistics including observed $\left(H_{\mathrm{O}}\right)$ and expected heterozygosity $\left(H_{\mathrm{E}}\right)$ were calculated using GENETIX 4.05 (Belkhir et al., 1996-2004), FSTAT (Goudet, 2001) and DnaSP 5.10.01 (Rozas, et al., 2003). $P$-values were adjusted for multiple comparisons using Bonferroni correction (Rice, 1989).

POWSIM 4.0 (Ryman and Palm, 2006) was used to assess the statistical power of all the markers, for detecting pairwise genetic differentiation at $F_{\mathrm{ST}}$ levels ranging from 0.00 to 0.20 . Overall $F_{\mathrm{ST}}$ (pairwise genetic differentiation), $F_{\text {IS }}$ (inbreeding coefficient) and $F_{\text {IT }}$ (deviation from HardyWeinberg proportions), were estimated with 10,000 permutations following Weir and Cockerham 
(1984). The significance of these estimates was then evaluated using 10,000 permutations for the respective populations (Excoffier and Schneider, 2005).

We tested for genetic structure using spatial autocorrelation (SAC; Smouse and Peakall, 1999) available in GENALEX 6 (Peakall and Smouse, 2006). This spatial autocorrelation coefficient was calculated using the genetic and geographic distance between individuals within distance classes (denoted as " $r$ "). A thousand random permutations were generated at $95 \%$ confidence intervals and when the data deviated significantly from the null hypothesis (a random geographic distribution) a positive SAC was identified. Under this model, geographically proximate samples will have a positive SAC, which decreases as the geographic distances increases. The point where SAC is not detected (where " $r "=0$ ), is known as the "patch size" and used as an indication of dispersal ability.

STRUCTURE 2.3.2 (Pritchard et al., 2000) a Bayesian clustering analysis method, was used to estimate the most likely number of populations $(K)$ based on allele sharing. Given the structure observed from sequence data we specified an admixture model with correlated allele frequencies among populations. We tested for 1-6 clusters $(K)$, with 20 iterations for each $K$. MCMC sampling of individual assignments to clusters continued for 200,000 generations, with 100,000 generations excluded as burn-in. We used the ln probability of the data and the ad hoc statistic $\Delta K$ (Evanno et al., 2005) to confirm the most likely number of populations with STRUCTURE HARVESTER (Earl and vonHoldt, 2012). Three dimensional Factorial Correspondence Analysis (FCA) in GENETIX 4.05 was also conducted on pairwise genetic distance between individuals (Belkhir et al., 1996-2004). This analysis allows a visual representation of the differences between individuals and how they cluster together. It is especially useful in high gene flow species with weak underlying structure.

An isolation-with-migration model (IMa 1.0) (Hey and Nielsen, 2007) was applied to the mtDNA and microsatellite datasets, separately and in combination. This software employs MCMC genealogical sampling to estimate posterior probabilities for mutational parameters of the ancestral $\left(\theta_{\mathrm{A}}\right)$ and daughter populations $\left(\theta_{1} ; \theta_{2}\right)$, the splitting time $(t$-split) and the extent/direction of migration between two daughter populations ( $m 1$ and $m 2$ ). For mtDNA sequence data, the HKY model was applied, allowing for multiple mutations at some nucleotide sites, along with rate calibration from analysis of divergence within $P$. capensis (section 2.7, below). Following pre-simulation runs to 
determine the upper bounds of the parameters, several independent runs were done to ensure mixing and consistent results. Parameter values were recorded every $1000^{\text {th }}$ generation with a burn-in of $2 \mathrm{x}$ $10^{6}$ generations. Runs were continued until an effective sample size (ESS) larger than 50 was obtained with no significant autocorrelation among parameter estimates. Once these criteria were met, three independent iterations were done with random seeds for each dataset. The posterior probability modes were used as parameter estimates with the $90 \%$ highest posterior density (HPD90) as credibility intervals.

\subsection{Distribution modelling}

Bioclimatic modelling with MaxEnt 3.3.3e (Phillips et al., 2006; Phillips and Dudik, 2008) was used to estimate the past, present and likely future distribution of rock hyrax in southern Africa. Sampled localities together with other validated occurrence records gave 271 point localities across the range of $P$. capensis capensis in southern Africa, beyond latitude $22^{\circ} \mathrm{S}$. This was reduced to 251 localities after filtering closely adjacent sampling sites to avoid over-representation of local climates.

For consistency across past, present and future models, we used the WorldClim spatial coverage's of 19 bioclimatic variables, at the 2.5-arc minute scale (http://www.worldclim.org/). Current climate coverages are estimated from global long-term observations. For past climates we used estimates derived from CCSM2 (Community Climatic system model) and MIROC (model on interdisciplinary research on climate) global circulation reconstructions for the last glacial maximum, $18 \mathrm{ka}$ (LGM). For predicted future climates we used CCSM4 and MIROC5 estimates (IPCC, 2050). Climate coverage's for each of 19 variables, in each of these five scenarios, were clipped to latitudes $12-37^{\circ} \mathrm{S}$, longitude $13-36^{\circ} \mathrm{E}$, and converted to ESRI ASCII files in QGIS using GDAL tools (QGIS Development Team, 2012-2013; QGIS A., 2015). These environmental layers were aligned and projected utilizing the Albers equal area clipped to the outline of southern Africa in QGIS. For modelling of current distribution we constructed 10 replicate models in MaxEnt from a random starting seed, with organismal data randomly divided into 70\% training (106 records) and 30\% test points (45 records), against a background of 10,000 "pseudo absence" points. We used jack-knife 
estimation of variable importance, with logistic output of occurrence likelihoods, and all other parameters left at default values. MaxEnt model performance was evaluated based on the average area under the Relative Operating Characteristic curve values (AUC) for test points, which reflect how accurately a model predicts the species presence, comparing the rate of true positive against false positive predictions of occurrence (sensitivity against 1-specificity) (Elith et al., 2011). The logistic model of optimal bio climates was then used as a query against each of the two past and two future climate estimates, giving spatial predictions of stability and change in rock hyrax occurrence through time.

\subsection{Phylogenetic analyses}

All sequenced loci were first analysed individually, followed by concatenation of data in FaBox 1.41 (Villesen, 2007) and analysis of this combined data matrix. As outgroups, a combination of the following species was selected depending on available sequencing information from GenBank or newly generated unpublished data from our group: Procavia capensis syriaca, Heterohyrax brucei, Dendrohyrax dorsalis, Loxodonta africana and Dugong dugon (accession numbers available in Supplementary Table S4). Phylogenetic models and their parameters (models of molecular evolution, length of MCMC analyses, different fossil calibrations and temperature of incrementally heated chains) were optimized prior to conducting final analyses using the Markov Chain Monte Carlo (MCMC) genealogical sampling method implemented by MrBayes and BEAST. For each locus the best fit model of evolution was selected based on the Akaike Information Criterion in JMODELTEST 0.1.1 (Posada, 2008) and these were used as prior settings for each run (cyt $b-\mathrm{TrN}+\mathrm{I}+\mathrm{G}$; AP5 TIM3; PRKC1 - HKY+G).

A final subset of 35 individuals which amplified across all gene regions, were used in subsequent analyses (Supplementary Table S4). Phylogenetic relationships were inferred using maximum likelihood (ML) in raxmlGUI 0.93 (Stamatakis, 2006; Silvestro and Michalak, 2012) and Bayesian approaches in MrBayes3.1.2 (Ronquist and Huelsenbeck, 2003) and BEAST 1.6.1 (Drummond and Rambaut, 2007). The ML analyses were conducted with GTR+G+I selected as the average best model 
for all loci and data sets. Confidence in nodes was assessed using 10,000 bootstrap replicates (Felsenstein, 1985), with nodes $<50 \%$ support collapsed to polytomies, and bootstrap values $>70 \%$ considered as strong support. Two replicate searches with $20 \times 10^{6}$ generations each, sampled every $1000^{\text {th }}$ generation, were conducted in MrBayes 3.1.2. Analyses in BEAST were similar to those described above (section 2.3) using an uncorrelated lognormal distributed relaxed clock model and a Yule speciation tree prior, with various approaches to rate calibration (described below). Maximum credibility trees were generated and summarized with TreeAnnotator1.6.1 (Rambaut and Drummond, 2010). FigTree 1.3.0 (Rambaut, 2009) was then used to view and draw the trees.

\subsection{Divergence time estimates}

An accurate estimation of the timing of evolutionary events is critical to the understanding of evolutionary forces that shape population diversity (Shapiro et al., 2004). We used a Bayesian framework, in BEAST 1.6.1, to date divergence of the major lineages found within P. capensis capensis and between this subspecies and other hyrax taxa. Three test runs: (i) with no constraints, (ii) with substitution rates, and (iii) with fossil calibrations, were used to estimate divergence dates between species and to verify the consistency of our results. The same models of evolution as above (section 2.6) were used. All date estimates were derived from molecular data, but were calibrated with well-supported fossil evidence from distantly related taxa. Three fossil calibration points were tested, namely (i) the hyrax and elephant-dugon split at 66-55 Ma (Springer et al., 1997; Gheerbrant, 2009); (ii) a fossil procaviid, Prohyrax, found in the Fayum region at $24 \mathrm{Ma}$, and (iii) a Heterohyrax-like fossil from Namibia, H. auricampensis, at between 10-3 Ma (Rasmussen et al., 1996; Seiffert, 2007). These calibrations points were applied with a normal prior and $95 \%$ credibility interval, as per by Rowe et al. (2008). A log-normal relaxed clock and a Yule prior distribution (Yule, 1924; Drummond et al., 2006) were selected. The MCMC analyses were run for $10 \times 10^{6}$ generations, with a burn-in of $1 \times 10^{6}$ generations and sampling every $10,000^{\text {th }}$ generation. TRACER 1.5 (Rambaut and Drummond, 2009) was used to visualize the estimated divergence times from the log file and to ensure that the chains had converged. FigTree 1.3.1 (Rambaut, 2009) was then used to construct the chronogram. 


\section{Results and Discussion}

\subsection{Genetic diversity and population structure (mitochondrial cytochrome b and nuclear introns)}

The mean base frequencies for cyt $b$ were similar to those reported in other studies on mammals (Irwin et al., 1991; Ducroz et al., 1998), with transition: transversion ratios typical of mitochondrial protein coding genes and a translated peptide sequence highly similar to that of other mammals (results not shown). The trimmed sequence of $786 \mathrm{bp}$ of the cyt $b$ gene for 110 individuals yielded 78 parsimony informative sites and 45 rock hyrax haplotypes (Table 1). Two major matrilineal lineages (haplogroups) are evident from different parts of southern Africa (Fig. 2): a lineage from northern South Africa (haplotypes Chb1-20) and a widespread southern lineage (haplotypes Chb21-44). These two haplogroups are separated by 12 mutational steps. The single Namibian sample ( $P$. capensis capensis Namibia, Chb45) clustered closest to the south with more than 10 mutations (not indicated in the network) between the core of the southern lineage and this haplotype.

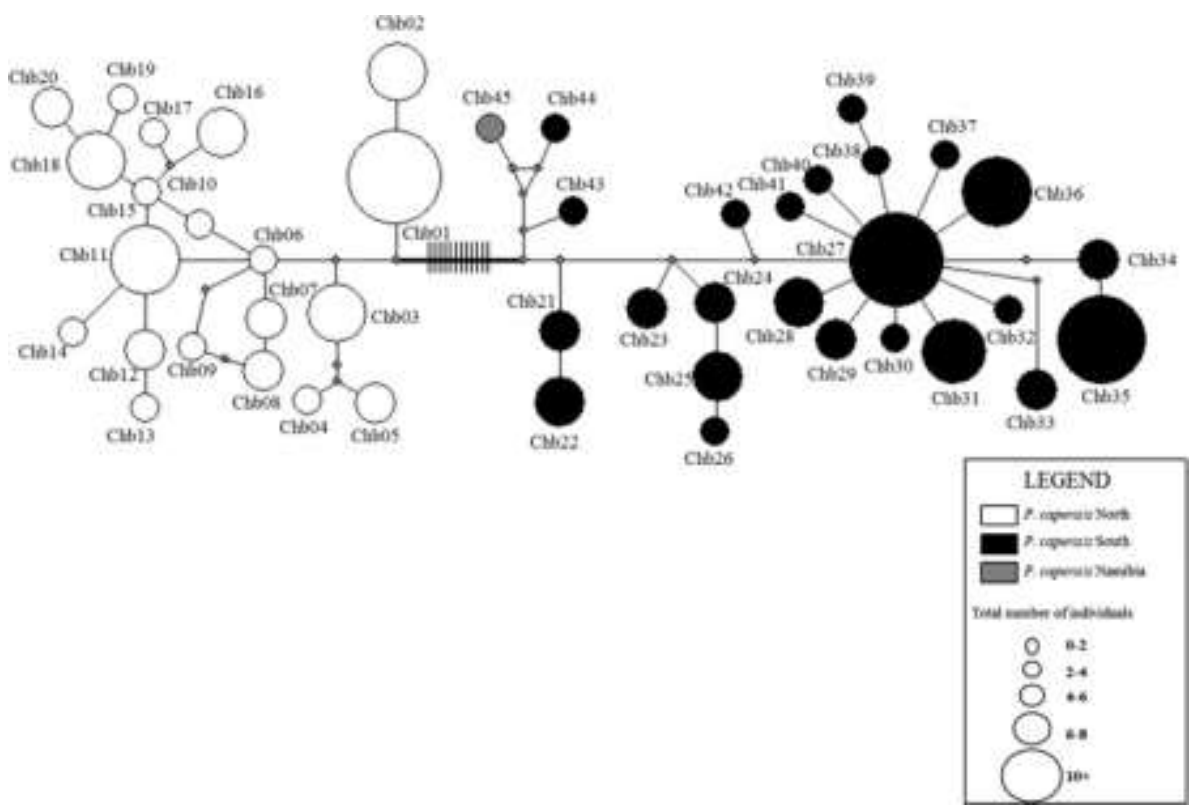

Fig. 2. Median joining haplotype network of Procavia capensis capensis from southern Africa reconstructed from mtDNA cytochrome $b$ sequences. Each circle represents a single haplotype; circle size is proportional to frequency of the haplotype (as per the key). Branch lengths are not proportional; each segment equals 1 mutation event between haplotypes. Black diamonds symbolize median vectors $(m v)$ representing hypothetical absent or unsampled ancestral haplotypes. The two lineages identified are the northern lineage in white (CHb01-21), the southern lineage in black (CHb22-44) and a Namibian haplotype in grey (CHb45). The vertical lines represent the minimum mutational steps between the two lineages. 
Sequencing of the nuclear introns AP5 and PRKC1 generated 304 bp (15 alleles) and 419 bp (21 alleles), respectively. No heterozygous sites were observed in PRKC1 and few heterozygous individuals were identified for AP5 (five of 45 sequences); this is likely as an artefact of selecting a subset of geographically dispersed samples and local fixation. In contrast to cyt $b$, only a few mutational steps (1-4) separate core clusters within the intron allele networks and these showed little phylogeographic structure and included some shared alleles across mitochondrially defined lineages. The allele network for AP5 includes two allele clusters, each with a central abundant allele (Cha01 and Cha05) and several singletons (Supplementary Fig. S2). Each of these allele clusters included multiple representatives from both mtDNA lineages. The PRKC1 allele network was more complex, with two major clusters consisting more of the southern mtDNA lineage than the northern one. Several associated singletons showed sub-structuring within clusters, with one sub-cluster (Chp08-11) spanning the range of the northern lineage, and a second including a roughly even contribution from the southern and northern mtDNA defined lineages (Chp13-16) (Supplementary Fig. S2).

Haplotype diversity at cyt $b$ was comparable between the two South African lineages, but nucleotide diversity was higher in the southern lineage (Table 1). The southern lineage was also characterized by significant Tajima's $D$ and negative $\mathrm{Fu} F$ s-values, consistent with demographic expansion. Nuclear intron PRKC1 had more parsimony informative sites, with higher haplotype diversity as compared to intron AP5 but both nuclear introns displayed comparable nucleotide diversities within lineages. Tajima's $D$ values were significant overall and in mtDNA defined populations at AP5 and overall and in the northern lineage at PRKC1. Fu's Fs was negative in all comparisons except for southern lineage PRKC1. The differences in phylogeographic structure inferred from mtDNA and nuclear loci may result from differences in lineage sorting between these markers, with greater retention of ancestral polymorphism at the intron loci. Alternatively, the observed pattern could suggest differential gene flow, possibly amplified by maternal philopatry and male dispersal, which has led to gene exchange after secondary contact. Male rock hyraxes are known to be the dispersers whilst females remain in their natal colonies (Hoeck et al., 1982; Fourie and Perrin, 1987; but see Gerlach and Hoeck, 2001 for contrasting results in P. c. johnstoni). 
Species histories are varied and complex, involving diverse processes, such as migration, admixture, isolation by distance, divergence in isolation or with gene flow, bottlenecks, and population growth, occurring over different time periods (Knowles, 2009). Our results confirm the presence of two well supported monophyletic maternal lineages within rock hyrax corroborating previous results based on mtDNA RFLP's (Prinsloo and Robinson, 1992) and limited mtDNA cyt $b$ sequencing (Prinsloo, 1993) (Fig. 2). The deep division found within the intraspecific mtDNA gene tree of these lineages ( $4.3 \%$ sequence divergence) with no shared haplotypes found among regions emphasizes the genetic distinctiveness of these southern African matrilines and suggests long-term isolation. The two lineages do not appear to be separated by discernible barriers to gene flow. A similar pattern of divergent lineages have been reported in other rock-dwelling or mountainassociated species from southern Africa such as Pronolagus rupestris (Matthee and Robinson, 1996) and Agama atra (Matthee and Flemming, 2002) although the time frame of the separations appears to differ.

The northern rock hyrax lineage is distributed across disjunct mountain ranges (Magaliesberg, Waterberg and Soutpansberg Mountains in Gauteng, North-West and Limpopo provinces, South Africa), mainly within the Limpopo River catchment but extending peripherally across the Vaal River, at the Vredefort Dome, Free State Province (Fig. 1). The northern limit of this lineage is unclear, although it extends to the limit of the Limpopo system in Zimbabwe (Prinsloo, 1993). The northern region of South Africa is characterised by rocky outcrops with vast stretches of intervening savannah or grassland habitat, such as the Springbok Flats. The most dominant haplotype in this group occurs around the southern limit (Chb01: Vredefort, Heidelberg and Silverton Ridge Pretoria). The remaining northern lineage haplotypes are distributed evenly throughout the region. This lineage extends to the Blyde River canyon at the northern extent of the southern lineage. The sparse scale of sampling here may be inadequate to capture local structuring of diversity across this topographically diverse area.

The southern lineage is more widespread, occurring across Cape Fold, Great Escarpment and Karoo mountains along with other isolated mountains and rock outcrops in the south. This lineage is bounded to the northwest by the central plateau of the Nama-Karoo biome and the semi-arid sandy 
Kalahari Desert (Fig. 1). The lineage loosely follows the Escarpment from the northwest to northeast ending at the Blyde River canyon (Mpumalanga Province, South Africa). The most abundant haplotype (Chb31) is widespread, spanning over $700 \mathrm{~km}$ east to west across the central range of this lineage, and forms a central hub in the allele network from which many other haplotypes radiate. Other relatively abundant haplotypes from this lineage are restricted to local areas, such as Koppies Dam (Chp35) and Bloemfontein (Chp36) in Free State Province, and may reflect uneven sampling (Fig. 1). Southern lineage haplotypes that are least divergent from the northern haplogroup (Chb4345) occur along the west and south coast and in the arid interior of South Africa, far from potential areas of contact between these lineages.

Both northern and southern haplogroups were characterized by a high proportion of private haplotypes which is congruent with hyrax fidelity to particular koppies in a matrix of unsuitable habitat. The southern and northern lineages abut across $500 \mathrm{~km}$, extending northeast from the northern Free State to Limpopo Province at the northern end of the Blyde River Canyon. Despite the proximity of sampling sites with different lineages across this line of demarcation, we did not find areas of sympatry. The higher number of singleton haplotypes and increased diversity in the southern haplogroup might be indicative of the greater extent of this lineage. The Mpumalanga-Limpopo Provinces axis of the escarpment in the Blyde River Canyon, Lydenberg and Olifants River gorge areas, for example, represents a potential place of secondary contact between the two lineages (Fig. 1). The separation between lineages in this area seems very narrow and needs to be investigated further. Thus mtDNA phylogeography in the rock hyrax seems to be the product of the dispersion of haplotypes among terrestrial islands.

\subsection{Microsatellite diversity and population structure}

Due to the limited number of microsatellite loci used in our study, the results on present levels of gene flow should be interpreted with caution. The number of alleles per locus ranged from 4 to 15 , across five loci that were consistently scored. A summary of the total number of alleles, allelic richness, average $H_{\mathrm{O}}, H_{\mathrm{E}}$ and $F_{\mathrm{IS}}$ for all locations is given in Supplementary Table A5. Expected 
heterozygosity ranged from 0.7 to 0.8 (Supplementary Table S5). No significant linkage disequilibrium was observed between loci within populations ( $\mathrm{P}>0.05$, after Bonferroni correction), although we found significant departures from expected Hardy-Weinberg proportions at all five loci. We included all loci in the final analyses due to the scarcity of available microsatellite loci and difficulty of amplification across species from published sources. Even though our species has high population numbers and low migration rates, the additive effect of the high sample numbers and diversity at the microsatellite loci act as replicates to add more power to the analyses (Dakin and Avise, 2004; Selkoe and Toonen, 2006). We found presence of null alleles at some loci (Hy-D49, HyT25, Hy-T17 and Hy-T12) using the program MICRO-CHECKER; this might be due to an excess of homozygous alleles detected in our dataset (frequencies between 0.04-0.22). The inbreeding coefficient $F_{\text {IS }}$ was significant across all loci in the rock hyrax $(P<0.05)$ (Supplementary Table S5). Significant differentiation was detected between the northern and southern mtDNA defined lineages $\left(F_{\mathrm{ST}}=0.09, P<0.001 ; R_{\mathrm{ST}}=0.08, P<0.001\right)$.

The most likely number of genetic clusters inferred using STRUCTURE was 1 and the $\Delta K$ indicated that the differences between $K=1-3$ were very small (Supplementary Fig. S4). Notwithstanding, the STRUCTURE plot at $K=2$ (Supplementary Fig. S5) and the FCA (data not shown) are consistent with the two mtDNA defined subpopulations, indicating some individuals that assign with high probability $(q)$ to a single genetic cluster while others appear to be admixed or migrants. On average, the southern lineage showed almost equal membership to the two inferred genetic clusters (52\% versus $48 \%$ ), while individuals sampled in the north on average showed $74 \%$ assignment to one of the genetic clusters; this result is in line with the inference of gene flow in IMa (refer to section 3.4). Given the low apparent allelic richness at the available microsatellite loci in rock hyrax (this study; Gerlach and Hoeck, 2001), there is likely also a substantial degree of retention of ancestral polymorphism between the local rock hyrax lineages.

Mantel tests did not show a significant correlation between geographic distances and genetic differentiation $(R=0.91, P=0.63)$, thus failing to reveal a pattern of isolation-by-distance. The preponderance of mtDNA private alleles suggests that there is some spatial structure among populations. We therefore employed spatial autocorrelation to further explore local structure in the 
microsatellite and combined data (mtDNA + five microsatellite loci). We assigned samples to three distance classes $(50 \mathrm{~km}, 100 \mathrm{~km}$ and $200 \mathrm{~km}$, between locations, respectively). The spatial autocorrelation statistics for the microsatellite data alone were positive and significant at 100 and 200 $\mathrm{km}(P=0.001, P=0.002$, respectively), with an $r$ intercept at $334 \mathrm{~km}$. The correlogram for the combined data set showed positive correlation at 0 to $200 \mathrm{~km}(P=0.001, P=0.002$, respectively), with the $r$ intercept at $370 \mathrm{~km}$ (Supplementary Fig. S6). These results reflect a clear local neighbourhood effect but with no discernible structure the further koppies are from each other. This inconsistency over larger distances may be due to the persistent effect of past changes in population size, distribution of the species and mixing between the lineages. Hyrax are known to undergo cycles of population declines and irruptions, these are thought to be driven by food availability and disease prevalence in certain areas, which in turn allows periodic species turn-over in times of distress.

\subsection{Population size and demographic changes over time}

Bayesian skyline analyses across both lineages suggested an expansion around 20-25 ka (Fig. 3 A). The northern lineage revealed a recent population decline at around $10 \mathrm{ka}$, whilst the southern lineage showed post-glacial decline around $18 \mathrm{ka}$ (Fig. $3 \mathrm{~B}$ and C). Although the mtDNA results from Tajima's $D$ and Fu's $F$ s were negative in both lineages, only in the southern lineage were these statistically significant (Table 1). This provides strong evidence that the southern lineage has recently experienced large population expansion and rules out other evolutionary factors that might produce similar patterns (Fu and Li, 1999) (Table 1; mismatch distribution plots are shown in Supplementary Fig. S3).

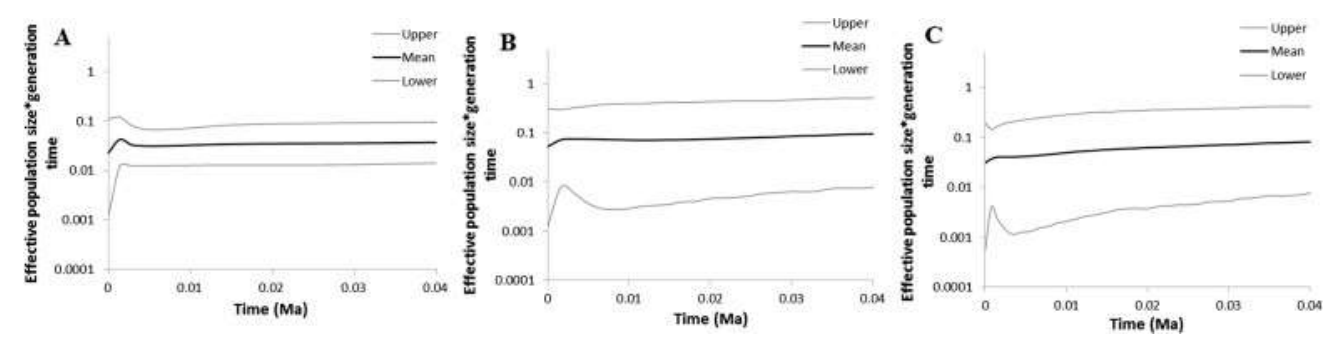

Fig. 3. Extended Bayesian skyline plots for the combined (A), northern (B) and southern (C) mtDNA groups in the rock hyrax. Skyline plots in A, B and C show estimated population size through time; black lines represent the median estimate of population size $(\mathrm{Neg})$, grey lines are the upper and lower $95 \%$ posterior intervals. 
The patterns evidenced from the intronic regions were similar, with the northern and southern lineages showing slightly different demographic trends based on neutrality tests (Table 1). In intron AP5 both the northern and southern lineage exhibited significant and negative Tajima's $D$ and Fu $F$ s. The diversity within the northern lineage was higher than the southern lineage, with the southern lineage showing a greater indication of expansion. On the contrary, the Prkc1 intron displayed similar unimodal distribution indicative of a recent population expansion for both the northern and southern lineages (results not shown). This was mirrored by the BSP results which indicated that this increase was gradual beginning at around 10 kya until recent times. Although the overall results for the BSP analyses and the neutrality estimates were concordant the stochastic nature of individual gene histories was also apparent (Table 1). These patterns are expected from introns due to the differences in their mutation rates, as well as the associated functions of the exonic regions.
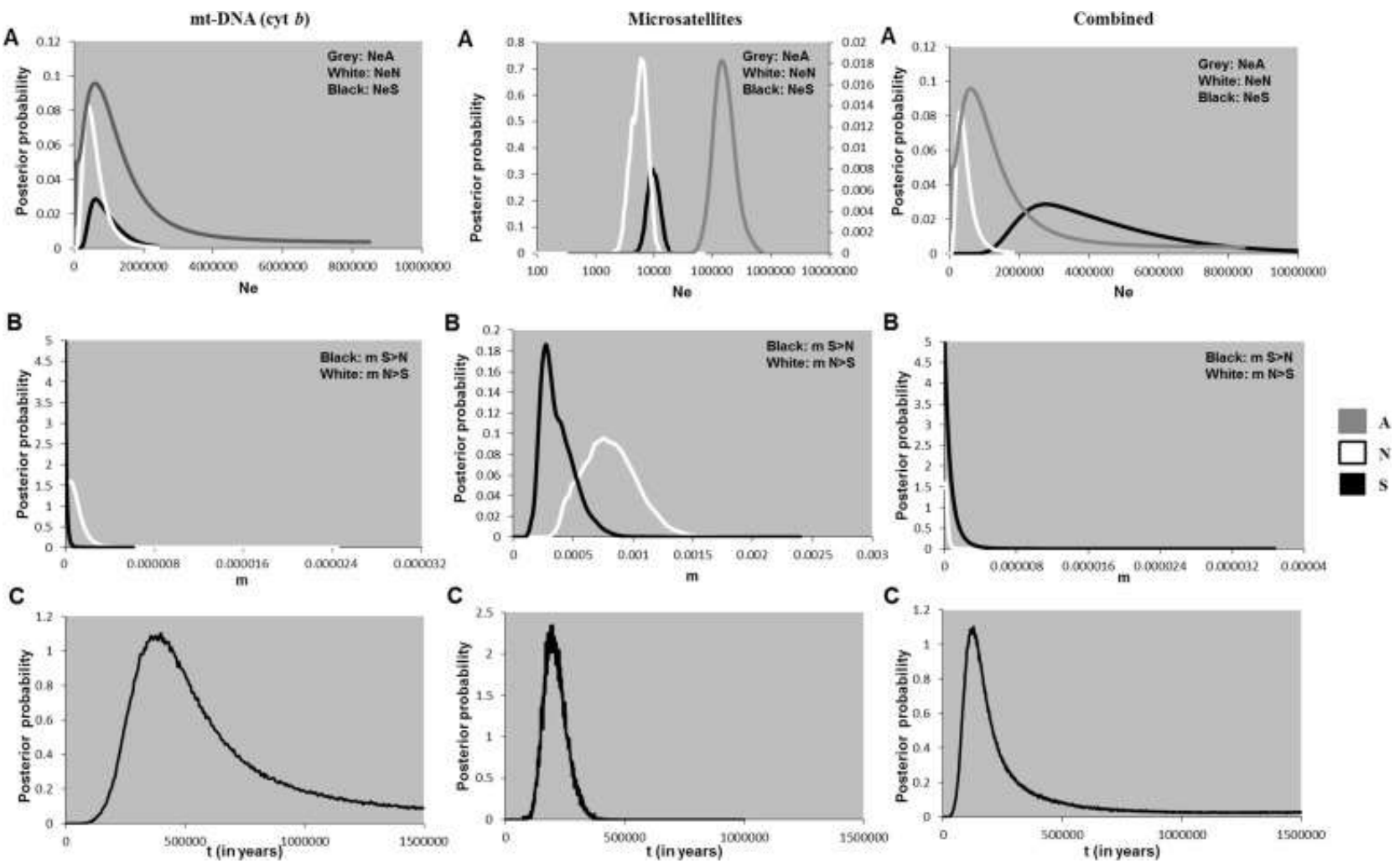

Fig. 4. Marginal posterior densities of coalescent parameters in Procavia capensis capensis as estimated in IMa for cyt $b$ (left), microsatellites (centre) and combined datasets (right). Each graph shows HPD distributions for ancestral (grey), northern (white), and southern lineages (black). Figure (A) shows effective population size ( $N e \mathrm{~A}, \mathrm{NeN}$ and $\mathrm{NeS}$, for each marker), (B) migration rates and (C) splitting time between lineages. 
Utilizing the IMa model to estimate demographic parameters from our individual and combined datasets, we obtained good ESS values (> 100) for the effective population size and migration rates, with well-defined marginal peaks for each lineage (Hey and Nielsen, 2007; Hey, 2005). Our explorations of the splitting time estimates were less conclusive, with lower ESS values and broad marginal distributions with long tails, especially for the mtDNA data. We used the HiPt values (highest value bin) in our calculations; the ancestral effective population size varied for mtDNA and microsatellite data $\left(\mathrm{NeA}=118 \times 10^{4} / 35.7 \times 10^{3}\right.$, respectively $)$. The southern lineage had a larger $N_{\mathrm{e}}$ than the northern lineage in both datasets $\left(\mathrm{NeN}=498 \times 10^{3} / 4.3 \times 10^{3} ; \mathrm{NeS}=515 \times 10^{3} / 5.6 \times 10^{3}\right)$ (Fig. 4A).

The mtDNA and combined analyses indicated isolation of lineages, with a possibility of very occasional gene flow from north to south. Analysis of microsatellite data suggested migration in both directions, but with higher gene flow from the northern into the southern lineage (Fig. 4B). Contemporary gene flow between the lineages was found to be low, with less than one effective migrant per generation, based on both the IMa and other analyses. Although our datasets indicated similar patterns of gene flow, we obtained varying divergence time estimates. We were unable to obtain precise estimates of the timing of splits between lineages, with the highest posterior density from around $210 \mathrm{ka}-235 \mathrm{ka}$ in the mtDNA analysis, $110 \mathrm{ka}$ in microsatellite analysis, to over $220 \mathrm{ka}$ in the combined analysis (Fig. 4C). These results indicate a period of stability, followed by isolation and recent secondary contact between lineages.

Ecological studies on hyrax have shown contrasting regional life-history traits (Turner et al., 1965; Kotler et al., 1999; Gerlach and Hoeck, 2001). Procavia c. capensis seems to have persisted in interconnected rocky outcrops across southern Africa, with multiple source populations for recolonizations during suitable environmental conditions. The ability of hyrax to traverse vast inhospitable intervening areas affects the connectivity between distant areas. Moreover, it is wellestablished that small amounts of gene flow could mask the genetic signal of distinction between separate populations (Chikhi et al., 2010). 


\subsection{Distribution modelling}

AUC (area under the Relative Operating Characteristic curve) values varied from $0.78-0.86$ across replicate models for test data (average 0.80 ), indicating consistently good model performance (Pearce and Ferrier, 2000). The variables contributing most to the jack-knifed test gain and AUC were: Precipitation in the Coldest Quarter (PCQ), Temperature in the Wettest Quarter (TWQ), and Precipitation in the Driest Month (PDM). In general the probability of occurrence increased with wet season rainfall and, less consistently, decreased with higher temperatures.

Predictions for current occurrence showed two broad distributional foci: one in the South-Western Cape, the other in the North-Eastern Highveld and Eastern Escarpment (Fig. 5). Other areas of high predicted occurrence include: the Great Escarpment, highlands of Namaqualand and Southern Namibia, including rocky sections along the lower Orange (Gariep) River, around and below Augrabies Falls, which is separated from the northern focal areas by the inhospitable Kalahari sands (Fig. 5). This model closely matches the inferred geographic distribution of each mtDNA haplogroup and lends support to the hypothesis that the genetic assemblages reflect a bioclimatic barrier to gene flow between the southern and northern areas (Fig. 5). A notable exception, however, is the eastern part of the Great Escarpment and adjacent grasslands, extending from the Free State and KwaZuluNatal Drakensberg through to northern Mpumalanga Province, which carry the southern mtDNA lineage but are in the north-eastern focal area of distribution (Supplementary Fig. S1).

Predicted areas with highly suitable bioclimates were somewhat more extensive during the LGM, with greater continuity and connectivity within and among regions (Fig. 5). Although both current and LGM models suggest connectivity between lineages, predictions from spatial modelling will often be wider than the actual occurrence of species, due to physical barriers and biotic interactions constraining the realized distribution (Phillips et al., 2006). Predictions from future climates suggest a modest contraction in range to the $\mathrm{NE}$ and $\mathrm{SW}$, decreasing the total occurrence and increasing the separation between these areas. Both models suggest limited contact between the northern and southern areas, with the main route of connection along the Great Escarpment found in the Mpumalanga-Limpopo axis of the escarpment (Clark et al., 2011). 

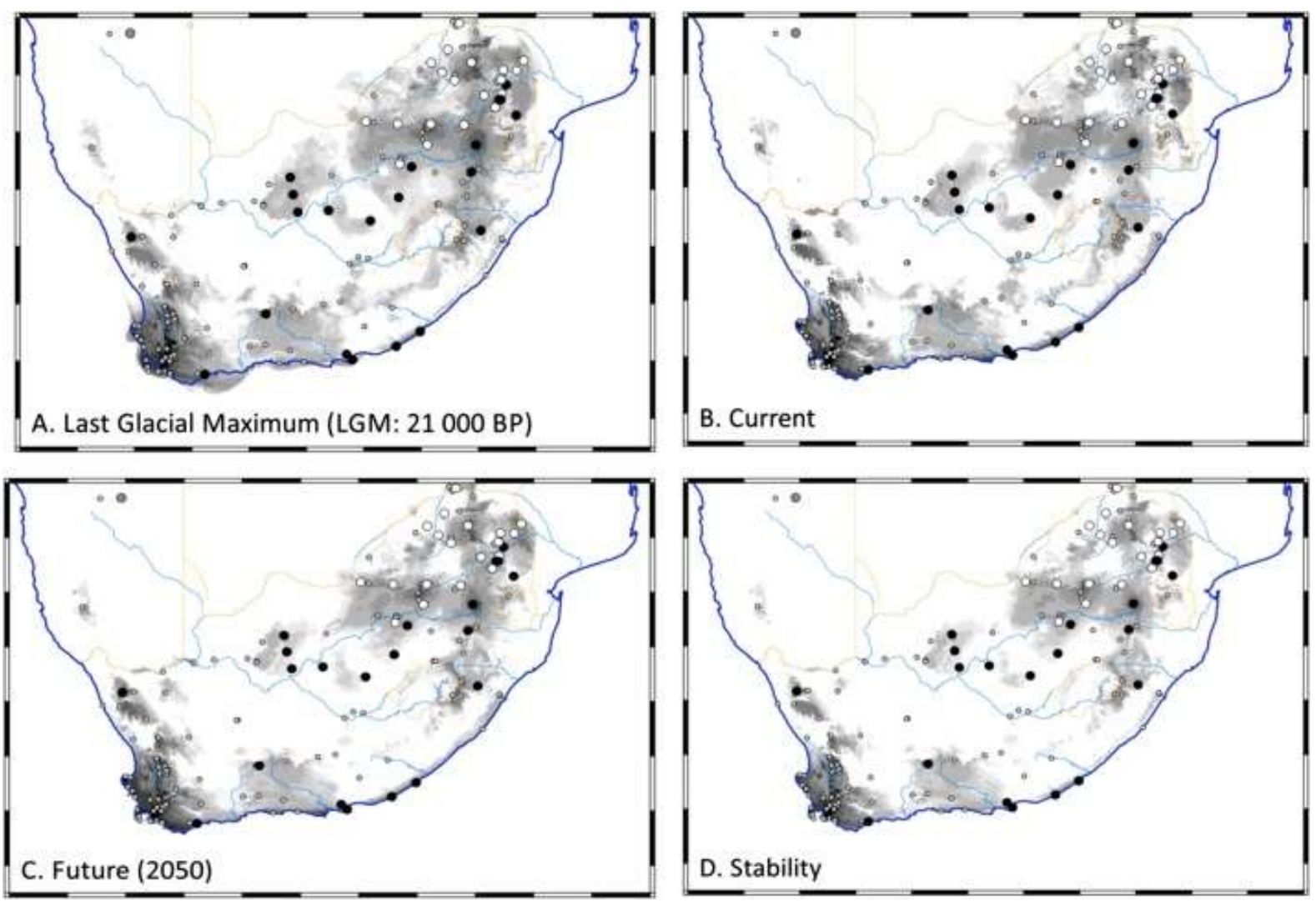

Fig. 5. MaxEnt bioclimatic distribution models for the rock hyrax in southern Africa. Black through to white shaded areas reflect decreasing probability of bioclimatic suitability. Panes show predictions for (A) past (LGM, $21 \mathrm{ka}$ ), (B) present, (C) future (2050) and (D) stability of occurrence, which is the intersection of the other three models. Localities with genetically analysed individuals are shown in white (northern) or black (southern lineage). Small grey circles represent presence data from other sources.

Both past and future models were robust to uncertainty in climate predictions, with little difference across CCSM or MIROC scenarios (data not shown). Consequently, the median of these models is shown in Fig. 5. The greatest separation evident is seen in the stability surface, which shows areas of consistent suitability across past, present and future climates. This surface also identified additional smaller isolated populations separated by consistent barriers. Some of these coincide with known biogeographic areas in southern Africa, such as the Knersvlakte separating the South-Western Cape from the Namaqualand highlands and with shallow genetic divergence within rock hyrax (Visser, 2013). Other distinct areas such as the Gaap plateau bordering the Kalahari, the Aggenys Mountains and Gariep gorge in the NW, and to a lesser extent, the Eastern Cape around Port Elizabeth, are not associated with known barriers. More extensive sampling is needed in these areas to elucidate the phylogeographic consequences of this environmental stability. 
The South African inland plateau is classified as mostly arid even though there is considerable variation in climate as well as topography. The SDM data suggest that $P$. capensis capensis lineages underwent dramatic changes in population size and connectivity in response to the climatic changes since the LGM. In particular, MaxEnt predictions for the northern lineage were much more extensive during the LGM than the current distribution (Fig. 5). Although these models are based entirely on bioclimates, it is worth noting that predicted unsuitable areas are dominated by sand, with few rocky outcrops. Occurrence was correlated with wet season rainfall making local adaptation likely in each lineage due to the reciprocal climate zones (summer versus winter wet season) in South Africa. We hypothesize that the geographic break between lineages persisted over the cooler climates of the Late Pleistocene (Deacon and Thackeray, 1983). Fossil hyrax varied significantly in size from place to place and this variation appears to be dependent on precipitation which would affect their food supply (Schwartz et al., 1995; Klein and Cruze-Uribe, 1996). Also based on the diverse environmental profile of southern Africa, rock hyraxes in different areas might be utilizing different refugial microclimates during unfavourable times. These areas could be used in a stepping stone manner during the interglacials for re-colonization, with locally adapted forms expanding to adjacent outcrops.

\subsection{Phylogenetic analyses and divergence time estimation}

Phylogenetic analyses recovered congruent topologies, regardless of approach used (RAxML, BEAST and MrBayes) (Fig. 6). The rock hyrax (Procavia capensis) was confirmed to be monophyletic with high posterior probability support (Fig. 6). Four deeply divergent, highly supported lineages were found among rock hyrax, including the two southern African lineages, the Middle Eastern P. c. syriaca and the Namibian lineage (currently assigned to P. c. capensis) (Fig. 6). The sister relationships between the three hyrax genera are unresolved (Fig. 6). Such high posterior probability support with long internal and short tip branches indicates long divergence within these lineages followed by rapid radiation. Combining the mitochondrial and nuclear data dramatically decreased the resolving power of the analyses (data not shown). In fact, some of our internal nodes 
within the species tree collapsed to unresolved polytomies. On the contrary we found high bootstrap and posterior probability support at the terminal nodes in our species tree.

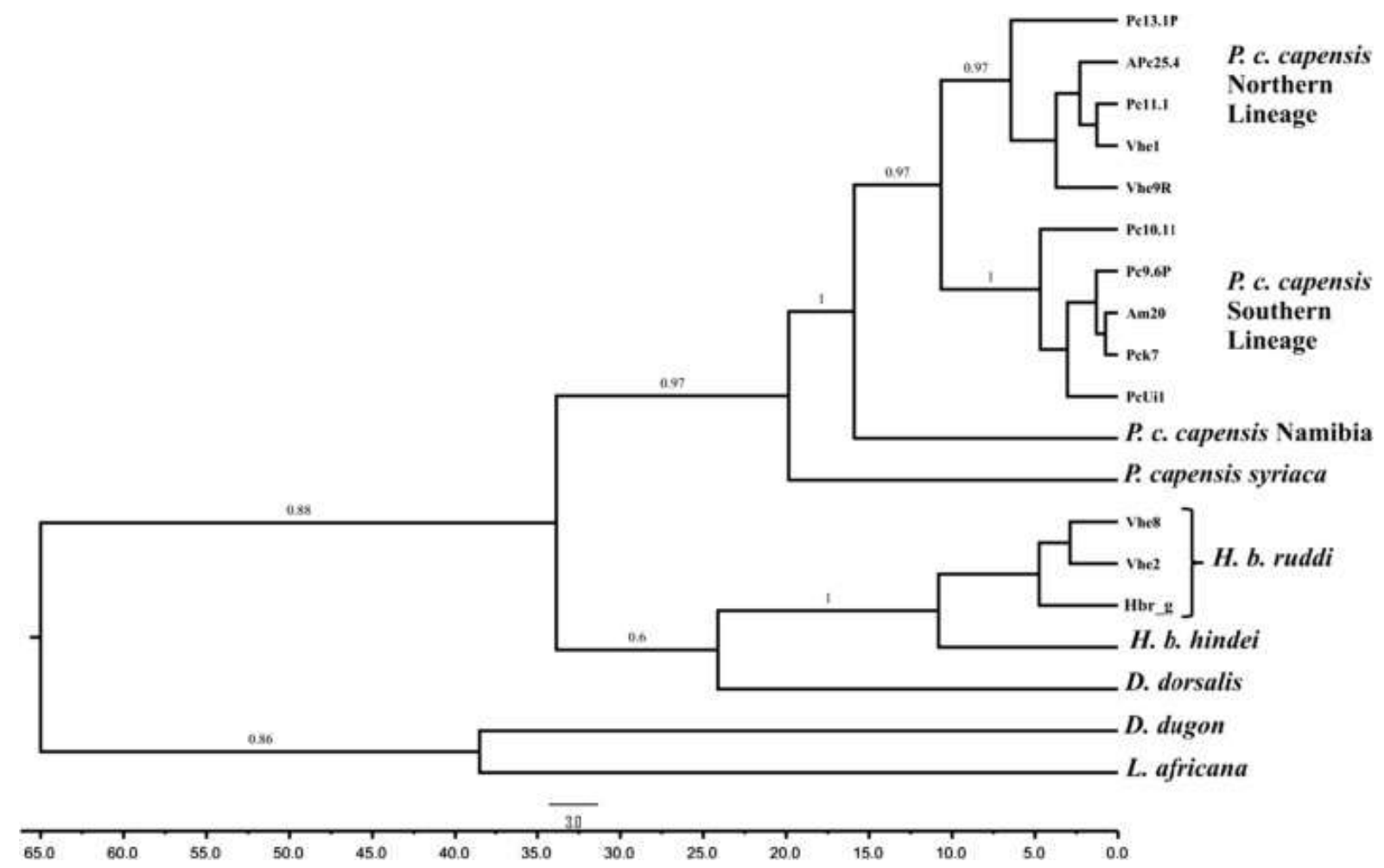

Fig. 6. Bayesian inference chronogram based on the cytochrome $b$ dataset for hyrax species and outgroups.

Lineages are labelled as: P. c. capensis northern/ southern lineages, $P$. c. capensis representatives from Namibia and P. c. syriaca from Israel, representatives of $H$. brucei subspecies, Dendrohyrax and with a sirenian (D. dugon) and a proboscidean (L. africana) as outgroups. Only well supported posterior probabilities for the nodes are indicated with asterisks.

Estimated times to common ancestry (TMRCA) in the hyrax phylogeny were used to infer the chronology of events that affect diversity within and between species. Earlier studies used only the paleontologically estimated splits within the Afrotheria or even deeper divergences to calibrate the hyrax molecular clock (Springer et al., 1997; Stanhope et al., 1998). More recent studies use Bayesian coalescent-based approaches that take into account both the deeper and recent splits to calibrate the molecular clock. Although the use of molecular clocks has been much debated and the estimation of divergence time is uncertain (Graur and Martin, 2004), we wanted to obtain tentative divergence times for the sibling species. The use of fossil data to calibrate phylogenetic trees has several disadvantages, such as errors in radioisotope dating, identifying the correct position of a fossil and incomplete records (Smith and Peterson, 2002; Lukoschek et al., 2012). However, using soft bounds 
(upper and lower bounds) reduces the amount of uncertainty introduced and allows cross-validation of divergence time estimates.

Congruent time estimates were obtained with two independent methods, a relaxed Bayesian molecular clock and a fossil calibrated coalescent approach in BEAST (Benton and Donoghue, 2007). According to fossil calibrated estimates, all three extant genera of hyrax diverged from each other during the Oligocene (25-30 Ma, Fig. 6). The most recent common ancestor of Procavia dates to 18$20 \mathrm{Ma}$. The split between southern and northern southern African populations of P. c. capensis occurred at about $10 \mathrm{Ma}$ (Fig. 6), a substantial increase on the 2 Ma estimated in the study by Prinsloo and Robinson (1992). We acknowledge that although our multilocus coalescence-based approach is currently the most comprehensive attempt to date the divergence in hyrax, the confidence interval spanning from the Pliocene into the Miocene epoch is large (Ho and Phillips, 2009).

Historical factors are generally expected to be more influential in taxa with comparatively low vagility, a common outcome being the detection of strongly defined associations between mtDNA haplotypes and geographic location (Honeycutt and Wheeler, 1990; Matthee and Robinson, 1996; Avise et al., 1997). When divergence between lineages occurs across a natural barrier to gene flow one might expect to find similar results from both mitochondrial and nuclear genomes. In our case this is not so with the nuclear genes introgressing after secondary contact between lineages and no signal of introgression observed in the mitochondrial genome. The lack of congruence between markers points to the retention of ancestral polymorphisms, as well as re-establishment of secondary contact between the two rock hyrax populations. Introgression may be influenced by sex-biased dispersal but this would need to be investigated further. The genetic break between the northern and southern lineages in hyrax is a fluid matrix which is influenced by ongoing climate change.

\section{Conclusion}

Our results confirm that the life history traits of a species are reinforced by different microclimatic variables that have contributed to the contemporary species distribution within rock hyrax from southern Africa. The deep phylogeographic division evident in the matrilineal lineages largely reflects fluctuating climatic barriers rather than permanent physical impediments to gene flow such as 
mountains, sandy deserts and rivers. Rather, the southern African rock hyraxes follow the extensive meander of the mountains and use these as refugia during unfavourable periods. These areas serve as sources for population expansion events during favourable times. Our study represents the most comprehensive phylogeographic investigation of the rock hyrax from southern Africa and will provide an important benchmark for future studies on procaviids from the region and beyond. Importantly, our results also show a complex pattern of long bouts of lineage isolation followed by periodic admixture due to secondary contact. The patterns of cladogenesis and diversity evidenced here point to a complexity in the genetic history of hyrax populations from southern Africa. Despite the marked differences in the terminal matrilineal lineages, the taxonomy in hyrax remains unclear. Future studies in hyrax should focus on these regions with regular sampling to better understand the maintenance of mitochondrial divergence between the north and south. Additionally, the contrasting signals can be better understood by doing multi-species comparisons across these koppies, as well as adopting a genomics approach which would give us a better suite of markers to help unravel the evolutionary history of southern African saxicolous species.

\section{Acknowledgements}

We are grateful to members of the Molecular Ecology and Evolution Programme (MEEP) in the Department of Genetics at the University of Pretoria, especially Dr K Reid for all the laboratory assistance. Miss BF Mashangoane is thanked for her constructive comments on earlier drafts of the manuscript. We would like to express our gratitude to Dr TB Hoareau for his help with some of the analyses. The study was funded by the National Research Foundation (NRF), South African Research Chair of Behavioural Ecology and Physiology and the L'Oréal/UNESCO for Women in Science subSaharan Africa. We acknowledge the University of Pretoria for the logistical and financial contributions towards the project. We are thankful to Prof MW Bruford and Dr IM Russo (Cardiff University) for help with microsatellite optimization. 


\section{References}

Allen, G.M., 1939. A checklist of African mammals. Bull. Mus. Comp. Zool. 83, 1-763.

Ashley, Mary, V., Dow B.D., 1994. The use of microsatellite analysis in population biology: background, methods and potential applications. EXS. 69, 185-201.

Avise, J.C., 2000. Phylogeography: the history and formation of species. Harvard University Press, Cambridge MA.

Avise, J.C., Wollenberg, K., 1997. Phylogenetics and the origin of species. Proc. Natl. Acad. Sci. USA. $94,7748-7755$.

Bandelt, H.J., Forster, P., Rohl, A., 1999. Median joining networks for inferring intraspecific phylogenies. Mol. Biol. Evol. 16, 37-48.

Barry, R.E., Shoshani, J., 2000. Heterohyrax brucei. Mamm. Species. 645, 1-7.

Belkhir, K., Borsa, P., Chikhi, L., Raufaste, N., Bonhomme, F., 1996-2004. GENETIX 4.05 Logiciel sous Windows pour la Genetique des Populations, Laboratoire Genome, Populations, Interactions, CNRS UMR 5171, Universite de Montpellier II, Montpellier (France).

Benton, M.J., Donoghue, P.C.J., 2007. Paleontological evidence to date the tree of life. Mol. Biol. Evol. 24, 26-53.

Bothma, J.D.P., 1971. Order Hyracoidea, in: Meester, J., Setzer, H.W. (Eds.), The mammals of Africa: an identification manual. Smithsonian Institution Press, Washington DC, Part 12, pp. $1-8$.

Carnaval, A.C., Hickerson, M.J., Haddad, C.F., Rodrigues, M. T., Moritz, C., 2009. Stability predicts genetic diversity in the Brazilian Atlantic forest hotspot. Science. 323, 785-789.

Chase, B.M., Meadows, M.E., 2007. Late Quaternary dynamics of southern Africa's winter rainfall zone. Earth Sci. Rev. 84, 103-138.

Chikhi, L., Sousa, V.C., Luisi, P., Goossens, B., Beaumont, M. A., 2010. The confounding effects of population structure, genetic diversity and the sampling scheme on the detection and quantification of population size changes. Genetics. 186, 983-995. 
Clark, R.V., Barker, N.P., Mucina, L., 2011. The Great Escarpment of southern Africa: a new frontier for biodiversity exploration. Biodivers. Conserv. 20, 2543-2561.

Clement, M., Posada, D., Crandall, K.A., 2000. TCS: a computer program to estimate gene genealogies. Mol. Ecol. 9, 1657-1659.

Coe, M.J., 1962. Notes on the habits of the Mount Kenya hyrax (Procavia johnstoni mackinderi Thomas). Proc. Zool. Soc. Lond. 138, 639-644.

Cowling, R.M., Procheş, Ş., Partridge, T.C., 2009. Explaining the uniqueness of the Cape flora: incorporating geomorphic evolution as a factor for explaining its diversification. Mol. Phylogenet. Evol. 51, 64-74.

Dakin, E.E., Avise J.C., 2004. Microsatellite null alleles in parentage analysis. Heredity. 93, 504-509.

Deacon, H.J., Thackeray, J.F., 1984. Late Pleistocene environmental changes and implications for the archaeological record in southern Africa, in: Vogel J.C., (Ed.), Late Cainozoic palaeoclimates of the southern hemisphere. Balkema, Rotterdam, pp. 375-390.

Drummond, A.J., Rambault, A., 2007. BEAST: Bayesian evolutionary analysis by sampling trees. BMC Evol. Biol. 7, 214-221.

Drummond, A.J., Ho, S.Y., Phillips, M.J., Rambaut, A., 2006. Relaxed phylogenetics and dating with confidence. Plos Biol. 4, 699.

Drummond, A.J., Rambaut, A., Shapiro, B.E., Pybus, O. G., 2005. Bayesian coalescent inference of past population dynamics from molecular sequences. Mol. Biol. Evol. 22, 1185-1192.

Ducroz, J., Volobouev, V., Granjon, L., 1998. A molecular perspective on the systematics and evolution of the genus Arvicanthus (Rodentia, Muridae): Inferences from complete cytochrome b gene sequences. Mol. Phylogenet. Evol. 10, 104-117.

Earl, D.A., and vanHoldt B.M., 2012. "STRUCTURE HARVESTER: a website and program for visualizing STRUCTURE output and implementing the Evanno method." Conservation Genet Resour. 4, 359-361.

Elith, J., Phillips, S.J., Hastie, T., Dudík, M., Chee, Y. E., Yates, C. J., 2011. A statistical explanation of maxent for ecologists. Divers. Distrib. 17, 43-57. 
Ellerman, J.R., Morrison-Scott T.C.S., Hayman, R.W., 1953. Southern African mammals 1758 to 1951: A reclassification. British Museum (Natural History), London.

Excoffier, L., Lischer, H.E.L., 2010. Arlequin suite ver 3.5: A new series of programs to perform population genetics analyses under Linux and Windows. Mol. Ecol. Res. 10, 564-567.

Evanno, G., Regnaut, S., Goudet, J., 2005. Detecting the number of clusters of individuals using the software STRUCTURE: a simulation study. Mol. Ecol. 14, 2611-2620.

Felsenstein, J., 1985. Confidence limits on phylogenies: an approach using the bootstrap. Evolution. 39, 783-791.

Fordham, D. A., Brook, B.W., Moritz, C., Nogués-Bravo, D., 2014. Better forecasts of range dynamics using genetic data. Trends Ecol. Evol. 29, 436-442.

Fourie, L.J., Perrin, M.R., 1987. Some new data on the reproductive biology of the rock hyrax. S. Afr. J. Wildl. Res. 17, 118-122.

Fourie, L.J., 1983. The population dynamics of the rock hyrax Procavia capensis (Pallas, 1766) in the Mountain Zebra National Park. Ph.D. Thesis, Rhodes University, Grahamstown, South Africa.

Fu, Y.X., 1997. Statistical tests of neutrality of mutations against population growth, hitchhiking and background selection. Genetics. 147, 915-925.

Fu, Y.X., Li W.H., 1999. Coalescing into the $21^{\text {st }}$ century: An overview and prospects of the coalescent theory. Theor. Popul. Biol. 56, 1-10.

Gerlach, G., Hoeck, H.N., 2001. Islands on the plains: metapopulation dynamics and female biased dispersal in hyraxes (Hyracoidea) in the Serengeti National Park. Mol. Ecol. 10, 2307-2317.

Gerlach, G., Derschum, H.S., Martin, Y., Brinkmann, H., 2000. Characterization and isolation of DNA microsatellite primers in hyrax species (Procavia johnstoni and Heterohyrax brucei, Hyracoidea). Mol. Ecol. 9, 1675-1677.

Gheerbrant, E., 2009. Paleocene emergence of the elephant relatives and the rapid radiation of African ungulates. Proc. Natl. Acad. Sci. USA. 26, 10717-10721. 
Gheerbrant, E., Peigné, S., Thomas, H., 2007. Première description du squelette d'un hyracoïde paléogène: Saghatherium antiquum de l'Oligocène inférieur de Jebel al Hasawnah, Libye. Palaeontogr. Abt A. 279, 93-145.

Goudet, J., 2001. FSTAT (version 2.9. 3): a program to estimate and test gene diversities and fixation indices. Updated from Goudet (1995). Available from http://www.unil.ch/izea/softwares/fstat.html.

Grant S.W., and Leslie R.W., 1993. Effect of metapopulation structure on nuclear and organellar DNA variability in semi-arid environments of southern Africa. S. Afr. J. Sci. 89, 287-293.

Graur, D., Martin, W., 2004. Reading the entrails of chickens: molecular timescales of evolution and the illusion of precision. Trends Genet. 20, 80-86.

Hare, M.P., Palumbi, S.R., 2003. High intron sequence conservation across three mammalian orders suggests functional constraints. Mol. Biol. Evol. 20, 969-978.

Harpending, H.C., Batzer, M.A., Gurven, M., Jorde, L. B., Rogers, A. R., Sherry, S. T., 1998. Genetic traces of ancient demography. Proc. Natl. Acad. Sci. USA. 95, 1961-1967.

Harpending, H.C., 1994. Signature of ancient population growth in a low-resolution mitochondrial DNA mismatch distribution. Hum. Biol. 66, 591-600.

Hewitt, G., 2011. Quaternary phylogeography: the roots of hybrid zones. Genetica. 139, 617-638.

Hewitt, G.M., 2004. Genetic consequences of climatic oscillations in the Quaternary. Philos. T. Roy. Soc. B. $359,183-195$.

Hewitt, G., 2000. The genetic legacy of the Quaternary ice ages. Nature. 405, 907-913.

Hey, J., Nielsen, R., 2007. Integration within the Felsenstein equation for improved Markov chain Monte Carlo methods in population genetics. Proc. Natl. Acad. Sci. USA. 104, 2785-2790.

Hey, J., 2005. On the number of New World founders: a population genetic portrait of the peopling of the Americas. Plos Biol. 3, 965.

Ho, S.Y., Phillips, M.J., 2009. Accounting for calibration uncertainty in phylogenetic estimation of evolutionary divergence times. Syst. Biol. 58, 1-13. 
Hoeck, H.N., 1982a. Population dynamics, dispersal and genetic isolation in two species of hyrax (Heterohyrax brucei and Procavia johnstoni) on habitat islands in the Serengeti. Z Tierpsychol. 59, 177-210.

Hoeck, H.N., Klein, H., Hoeck, P., 1982b. Flexible social organization in hyrax. Z. Tierpsychol. 59, $265-298$.

Hoeck, H.N., 1975. Differential feeding behaviour of the sympatric hyrax Procavia johnstoni and Heterohyrax brucei. Oecologia (Berl). 22, 15-47.

Hoeck, H.N., 1989. Demography and competition in Hyrax. A 17 years study. Oecologia. 79, 353360.

Honeycutt, R.L., Wheeler, W.C., 1990. Mitochondrial DNA: variation in humans and higher primates, in: Dutta S.K., Winter W. P., (Eds.), DNA systematics: humans and higher primates. CRC Press, Boca Raton, Florida, pp. 91-129.

Hudson, R.R., Coyne, J.A., 2002. Mathematical consequences of the genealogical species concept. Evolution. 568, 1557-1565.

Irwin, D.M., Kocher, T.D., Wilson, A.C., 1991. Evolution of the cytochrome b gene of mammals. J. Mol. Evol. 32, 128-144.

Johnson, M.R., Anhaeusser C.R., Thomas, R.J., 2006. The Geology of South Africa. The Geological Society of South Africa, Johannesburg.

Kingdon, J., 1990. Island Africa: the evolution of Africa's rare animals and plants. London, Collins. Kingdon, J., Happold, D., Hoffmann, M., Butynski, T., Happold, M., Kalina, J., (Eds.). 2013. Mammals of Africa (Vol. I). Introductory chapters and Afrotheria. Bloomsbury, London

Klein, R.G., Cruz-Uribe, K., 1996. Size variation in the rock hyrax (Procavia capensis) and Late Quaternary climatic change in South Africa. Quaternary Res. 46, 193-207.

Knowles, L.L., 2009. Statistical phylogeography. Annu. Rev. Ecol. Evol. S. 40, 593-612.

Kok, A.D., Parker, D.M., Barker, N.P., 2012. Life on high: the diversity of small mammals at high altitudes in South Africa. Biodivers. Conserv. 21, 2823-2843.

Kotler, B.P., Brown, J.S., Knight, M.H., 1999. Habitat and patch use by hyraxes: there's no place like home? Ecol. Lett. 2, 82-88. 
Koren, L., Geffen, E., 2011. Individual identity is communicated through multiple pathways in male rock hyrax (Procavia capensis) songs. Behav. Ecol. Sociobiol. 65, 675-684.

Körner, C., Paulsen, J., Spehn, E.M., 2011. A definition of mountains and their bioclimatic belts for global comparisons of biodiversity data. Alp. Bot. 121, 73-78.

Körner, C., 2004. Mountain biodiversity, its causes and function. Ambio. 33, 11-17.

Lensing, J.E., 1979. Feeding habits of the rock hyrax, Procavia capensis (Pallas, 1766), in Southern South West Africa. Doctoral dissertation, University of Pretoria.

Librado, P., Rozas, J., 2009. Dnasp v5: a software for comprehensive analysis of DNA polymorphism data. Bioinformatics. 25, 1451-1452.

Linder, H.P., 2003. The radiation of the Cape flora, southern Africa. Biol Rev.78, 597-638.

Lukoschek, V., Keogh, J.S., Avise, J.C., 2012. Evaluating fossil calibrations for dating phylogenies in light of rates of molecular evolution: a comparison of three approaches. Syst. Biol. 61, 22-43.

Makhubo, B.G., Tolley, K.A., Bates, M.F., 2014. Molecular phylogeny of the Afroedura nivaria (Reptilia: Gekkonidae) species complex in South Africa provides insight on cryptic speciation. Mol. Phylogenet. Evol. 82, 31-42.

Mantel, N., 1967. Ranking procedures for arbitrarily restricted observation. Biometrics. 65-78.

Matthee, C.A., Flemming, A.F., 2002. Population fragmentation in the southern rock agama, Agama atra: more evidence for vicariance in Southern Africa. Mol. Ecol. 11, 465-471.

Matthee, C.A., Robinson, T.J., 1996. Mitochondrial DNA differentiation among geographical populations of Pronolagus rupestris, Smith's red rock rabbit (Mammalia: Lagomorpha). Heredity. 76, 514-523.

McCarthy, T., Rubidge, B., 2005. The Story of Earth \& Life. Struik Publishers, Cape Town.

Meester, J.A.J., Rautenbach, I.L., Dippenaar, N.J., Baker L. M., 1986. Classification of southern African mammals. Transvaal Mus. Monograph. 5, 1-359.

Murata, Y., Nikaido, M., Sasaki, T., Cao, Y., Fukumoto, Y., Hasegawa, M., Okada, N., 2003. Afrotherian phylogeny as inferred from complete mitochondrial genomes. Mol. Phylogenet. Evol. 28, 253-260. 
Nei, M., Kumar, S., 2000. Molecular Phylogenetics and Evolution. Oxford University Press, New York.

Nei, M., 1987. Molecular evolutionary genetics. Columbia University Press, USA.

Ollier, C., Pain, C., 2000. The Origin of Mountains. Routledge, London.

Pamilo, P., Nei, M., 1988. Relationships between gene trees and species trees. Mol. Biol. Evol. 5, $568-583$.

Smouse, P.E., Peakall R., 1999. Spatial autocorrelation analysis of individual multiallele and multilocus genetic structure. Heredity. 82, 561-573.

Peakall, R.O.D., Smouse, P.E., 2006. GENALEX 6: genetic analysis in Excel. Population genetic software for teaching and research. Mol Ecol Notes. 6, 288-295.

Partridge, T.C., Botha, G.A., Haddon, I.G., 2006. Cenozoic deposits of the interior. In: Johnson, M.R., Anhaeusser C.R., Thomas, R.J. (Eds), The Geology of South Africa. The Geological Society of South Africa, Johannesburg, pp. 585-604.

Phillips, S.J., Dudík, M., 2008. Modeling of species distributions with Maxent: new extensions and a comprehensive evaluation. Ecography. 31, 161-175.

Phillips, S.J., Anderson, R.P., Schapire, R.E., 2006. Maximum entropy modeling of species geographic distributions. Ecol Model. 190, 231-259.

Posada, D., 2008. Jmodeltest: phylogenetic model averaging. Mol. Biol. Evol. 7, 1253-1256.

Prager, E.M., Tichy, H., Sage, R.D., 1996. Mitochondrial DNA sequence variation in the eastern house mouse, Mus musculus: comparison with other house mice and report of a 75-bp tandem repeat. Genetics. 143, 427-446.

Prinsloo, P., 1993. Molecular and chromosomal phylogeny of the Hyracoidea. PhD. Thesis, University of Pretoria, South Africa.

Prinsloo, P., Robinson, T.J., 1992. Geographic mitochondrial DNA variation in the rock hyrax, Procavia capensis. Mol. Biol. Evol. 9, 447-456.

Pritchard, J.K., Stephens, M., Donnelly, P., 2000. Inference of population structure using multilocus genotype data. Genetics. 155, 945-959.

QGIS, A., 2015. Free and Open Source Geographic Information System. 
QGIS Development Team., 2012-2013. QGIS geographic information system. Open Source Geospatial Foundation Project http://qgis. osgeo. org.

Rambaut, A., and Drummond A.J., 2010. "TreeAnnotator v1. 6.1." Available as part of the BEAST package at http://beast.bio.ed.ac.uk.

Rambaut, A., Drummond, A.J., 2009. Figtree v1.3.1. Available at http://beast.bio.ed.ac.uk/figtreefigtree.

Rambaut, A., Drummond, A.J., 2007. Tracer v1. 4: MCMC trace analyses tool. Available at http://beast.bio.ed.ac.uk/Tracer.

Rasmussen, D.T., Pickford, M., Mein, P., Senut, B., Conroy, G. C., 1996. Earliest known procaviid hyracoid from the late Miocene of Namibia. J. Mammal. 77, 745-754.

Rasmussen, D.T., 1989. The evolution of the Hyracoidea: a review of the fossil evidence, in: Prothero, D.R., Schoch, R.M., (Eds.), The evolution of perissodactyls. Oxford University Press, New York, pp. 57-78.

Rice, W.R., 1989. Analyzing tables of statistical tests. Evolution. 43, 223-225.

Rogers, A.R., Harpending, H., 1992. Population growth makes waves in the distribution of pairwise genetic differences. Mol. Biol. Evol. 9, 552-569.

Ronquist, F., Huelsenbeck, J.P., 2003. MRBAYES 3: Bayesian phylogenetic inference under mixed models. Bioinformatics. 19, 1572-1574.

Rousset, F., 2008. Genepop'007: A complete reimplementation of genepop software for Windows and Linux. Mol. Ecol. Resour. 8, 103-106.

Rousset, F., 1997. Genetic differentiation and estimation of gene flow from F-statistics under isolation by distance. Genetics. 145, 1219-1228.

Rousset, F., Raymond, M., 1995. Testing heterozygote excess and deficiency. Genetics. 140, 14131419.

Rowe, K.C., Reno, M.L., Richmond, D.M., Adkins, R. M., Steppan, S. J., 2008. Pliocene colonization and adaptive radiations in Australia and New Guinea (Sahul): multilocus systematics of the old endemic rodents (Muroidea: Murinae). Mol. Phylogenet. Evol. 47, 84-101. 
Rozas, J., Sánchez-delbarrio, J.C., Messeguer, X., Rozas, R., 2003. Dnasp, DNA polymorphism analyses by the coalescent and other methods. Bioinformatics. 19, 2496-2497.

Ryman, N., Palm, S., 2006. POWSIM: a computer program for assessing statistical power when testing for genetic differentiation. Mol. Ecol. Notes. 6, 600-602.

Sale, J.B., 1965. The feeding behaviour of rock hyraxes (genera Procavia and Heterohyrax) in Kenya. E. Afr. Wildl. J. 3, 1-18.

Sale, J.B., 1966. The habitat of the rock hyrax. J.E. Afr. Nat. Hist. Soc. 25, 205-214.

Sandel, B., Arge, L., Dalsgaard, B., Davies, R. G., Gaston, K. J., Sutherland, W. J., Svenning, J. C., 2011. The influence of late quaternary climate-change velocity on species endemism. Science. $334,660-663$.

Schneider, S., Excoffier, L., 1999. Estimation of past demographic parameters from the distribution of pairwise differences when the mutation rates vary among sites: application to human mitochondrial DNA. Genetics. 152, 1079-1089.

Schneider, C.J., Cunningham, M., Moritz, C., 1998. Comparative phylogeography and the history of endemic vertebrates in the Wet Tropics rainforests of Australia. Mol. Ecol. 7, 487-498.

Schlötterer, C., Pemberton, J., 1994. The use of microsatellites for genetic analysis of natural populations, in: Schierwater, B., Streit, B., Wagner, G.P., DeSalle, R. (Eds.), Molecular ecology and evolution: Approaches and applications. Birkhäuser, Basel, pp. 203-214.

Schwartz, G.T., Rasmussen, D.T., Smith, R.J., 1995. Body-size diversity and community structure of fossil hyracoids. J. Mammal. 76, 1088-1099.

Seiffert, E.R., 2007. A new estimate of afrotherian phylogeny based on simultaneous analysis of genomic, morphological, and fossil evidence. BMC Evol. Biol. 7, 224.

Selkoe, K.A., Toonen, R.J., 2006. Microsatellites for ecologists: a practical guide to using and evaluating microsatellite markers. Ecol. Lett. 9, 615-629.

Shapiro, B., Drummond, A.J., Rambaut, A., Wilson, M. C., Matheus, P. E., Sher, A. V., et al., 2004. Rise and fall of the Beringian steppe bison. Science. 306, 1561-1565. 
Silvestro, D., Michalak, I., 2012. raxmlGUI: a graphical front-end for RAxML. Org. Divers. Evol. 12, $335-337$.

Skinner, J.D., Chimimba, C.T., 2005. The Mammals of southern African subregion, $3^{\text {rd }}$ ed. Cambridge University Press, Cape Town.

Slatkin, M., 1993. Isolation by distance in equilibrium and non-equilibrium populations. Evolution. $47,264-279$.

Slatkin, M., Hudson, R.R., 1991. Pairwise comparisons of mitochondrial DNA sequences in stable and exponentially growing populations. Genetics. 129, 555-562.

Smethurst, D., 2000. Mountain geography. Geogr. Rev. 90, 35-56.

Smit, H.A., Robinson, T.J., van Vuuren, B.J., 2007. Coalescence methods reveal the impact of vicariance on the spatial genetic structure of Elephantulus edwardii (Afrotheria, macroscelidea). Mol. Ecol. 16, 2680-2692.

Smith, A.B., Peterson, K.J., 2002. Dating the time of origin of major clades: molecular clocks and the fossil record. Annu. Rev. Earth Pl. Sc. 30, 65-88.

Spehn, E.M., Rudmann-Maurer, K., Körner, C., 2011. Mountain Biodiversity. Plant Ecol Divers. 4, $301-302$.

Springer, M.S., Meredith, R.W., Janecka, J.E., Murphy, W. J., 2011. The historical biogeography of Mammalia. Philos. T. Roy. Soc. B. 366, 2478-2502.

Springer, M.S., Murphy, W.J., Eizirik, E., O'Brien, S. J., 2003. Placental mammal diversification and the Cretaceous-Tertiary boundary. Proc. Natl. Acad. Sci. USA. 100, 1056-1061.

Springer, M.S., Amrine, H.M., Burk, A., Stanhope, M. J., 1999. Additional support for Afrotheria and Paenungulata, the performance of mitochondrial versus nuclear genes, and the impact of data partitions with heterogeneous base composition. Syst. Biol. 48, 65-75.

Springer, M.S., Cleven, G.C., Madsen, O., de Jong, W. W., Waddell, V. G., Amrine, H. M., Stanhope, M. J., 1997. Endemic African mammals shake the phylogenetic tree. Nature. 388, 61-63.

Stamatakis, A., 2006. RAxML-VI-HPC: maximum likelihood-based phylogenetic analyses with thousands of taxa and mixed models. Bioinformatics. 22, 2688-2690. 
Stanhope, M. J., Madsen, O., Waddell, V.G., Cleven, G. C., de Jong, W. W., Springer, M. S., 1998. Highly congruent molecular support for a diverse superordinal clade of endemic African mammals. Mol. Phylogenet. Evol. 9, 501-508.

Swart, B.L., Tolley, K.A., Matthee, C.A., 2009. Climate change drives speciation in the southern rock agama (Agama atra) in the Cape Floristic Region, South Africa. J. Biogeogr. 36, 78-87.

Svenning, J.C., Fløjgaard, C., Marske, K.A., Nógues-Bravo, D., Normand, S., 2011. Applications of species distribution modeling to paleobiology. Quat. Sci. Rev. 30, 2930-2947.

Taberlet, P., Fumagalli, L., Wust-Saucy, A. G., Cosson J. F., 1998. Comparative phylogeography and postglacial colonization routes in Europe. Mol. Ecol. 7, 453-464.

Tabuce, R., Mahboubi, M., Sudre, J., 2001. Reassessment of the Algerian Eocene hyracoid Microhyrax. Consequences on the early diversity and basal phylogeny of the order Hyracoidea (Mammalia). Eclogae Geol. Helv. 94, 537-545.

Tajima, F., 1983. Evolutionary relationship of DNA sequences in finite populations. Genetics. 105, $437-460$.

Tamura, K., Stecher, G., Peterson, D., Filipski, A., Kumar, S., 2013. MEGA6: Molecular Evolutionary Genetics Analysis Version 6.0. Mol. Biol. Evol. 30, 2725-2729.

Templeton, A.R., Crandall, K.A., Sing, C.F., 1992. A cladistic analysis of phenotypic associations with haplotypes inferred from restriction endonuclease mapping and DNA sequence data. III. Cladogram estimation. Genetics. 132, 619-633.

Thompson, J.D., Gibson, T.J., Plewniak, F., Jeanmougin, F., Higgins, D. G., 1997. The CLUSTAL_X windows interface: flexible strategies for multiple sequence alignment aided by quality analysis tools. Nucleic Acids Res. 25, 4876-4882.

Turner, M.I.M., Watson, R.M., 1965. An introductory study on the ecology of hyrax (Dendrohyrax brucei and Procavia johnstoni) in the Serengeti National Park. E. Afr. WIildl. J. 3, 49-60.

Van Der Horst, C.J., 1941. On the size of the litter and the gestation period of Procavia capensis. Science. 93, 430-431. 
Van Oosterhout, C., Hutchinson, W.F., Wills, D.P., Shipley, P., 2004. MICRO-CHECKER: software for identifying and correcting genotyping errors in microsatellite data. Mol. Ecol. Notes. 4, $535-538$.

Villesen, P., 2007. FaBox: an online toolbox for fasta sequences. Mol. Ecol. Notes. 7, 965-968.

Visser, J.H., 2013. Gene-flow in the rock hyrax (Procavia capensis) at different spatial scales. Ph.D. Thesis, Stellenbosch University.

Waltari, E., Hijmans, R.J., Peterson, A.T., Nyári, Á.S., Perkins, S.L., Guralnick, R.P., 2007. Locating Pleistocene refugia: comparing phylogeographic and ecological niche model predictions. Plos One. 2, e563.

Watterson, G.A., 1975. On the number of segregating sites in genetical models without recombination. Theor. Popul. Biol. 7, 256-276.

Weir, B.S., Cockerham, C.C., 1984. Estimating F-statistics for the analysis of population structure. Evolution. 1358-1370.

Yule, G.U., 1924. The function of statistical method in scientific investigation. HM Stationery Office, UK. 


\section{Appendix A. Supporting material}

Supplementary Table S1: Geographic coordinates of all sampling localities of Procavia capensis from Southern Africa used in this study. Biome and bioregion terminology correspond to those of Mucina \& Rutherford (2006).

\begin{tabular}{|c|c|c|c|}
\hline LOCALITY & COUNTRY & PROVINCE & $\begin{array}{l}\text { GEOGRAPHIC } \\
\text { COORDINATE }\end{array}$ \\
\hline 1. Blackhills Farm & South Africa & Limpopo & -23.7372530 .65705 \\
\hline 2. Bloemfontein & South Africa & Free State & -29.099526 .23341 \\
\hline 3. Blouberg & South Africa & Limpopo & -23.1179228 .91924 \\
\hline 4. Blyde River Nature Reserve & South Africa & Limpopo & -24.604130 .8157 \\
\hline 5. Campbell & South Africa & Northern Cape & -28.8037323 .71121 \\
\hline 6. Danielskuil & South Africa & Northern Cape & -28.1667523 .55214 \\
\hline 7. De Hoop Nature Reserve & South Africa & Western Cape & -34.3783420 .54203 \\
\hline 8. East London & South Africa & Eastern Cape & -32.9668527 .96696 \\
\hline 9. Ermelo & South Africa & Mpumalanga & -26.4737729 .93995 \\
\hline 10. Heidelberg (Suikerbosrand) & South Africa & Gauteng & -26.4528 .217 \\
\hline 11. Hoedspruit (Lissataba) & South Africa & Limpopo & -24.2845830 .78668 \\
\hline 12. Howick & South Africa & KwaZulu-Natal & -29.4231930 .0852 \\
\hline 13. Jacobsdal & South Africa & Free State & -29.1292824 .77571 \\
\hline 14. Karoo National Park & South Africa & Northern Cape & -32.1589321 .92063 \\
\hline 15. Koppies Dam Nature reserve & South Africa & Free State & -27.2712727 .67159 \\
\hline 16. Kimberley & South Africa & Northern Cape & -28.7409824 .75719 \\
\hline 17. Kuruman & South Africa & Northern Cape & -27.5691223 .40208 \\
\hline 18. Farm: Witberg 295, Kuruman & South Africa & Northern Cape & -27.1942922 .48125 \\
\hline 19. Letaba, Kruger National Park & South Africa & Limpopo & -23.9227731 .26659 \\
\hline 20. Lydenburg & South Africa & Mpumalanga & -25.1161630 .57963 \\
\hline 21. Maqili, Kruger National Park & South Africa & Mpumalanga & -25.434131 .32887 \\
\hline 22. Marken & South Africa & Limpopo & -23.7431828 .45754 \\
\hline 23. Matopo Hills, Zimbabwe & Zimbabwe & & -20.5571828 .5125 \\
\hline 24. Mica & South Africa & Limpopo & -24.0659430 .81335 \\
\hline 25. Middelburg & South Africa & Mpumalanga & -25.6433729 .29603 \\
\hline 26. Morgenson (Roodekrans) & South Africa & Mpumalanga & -26.6909429 .59476 \\
\hline 27. Munnik (Mooketsi) & South Africa & Limpopo & -23.6443430 .02002 \\
\hline
\end{tabular}




\begin{tabular}{||l|l|l|l||}
\hline 28. Namibia & Namibia & & -22.5501517 .85024 \\
29. Pilgrim's Rest & South Africa & Mpumalanga & -24.8653130 .75643 \\
30. Potgietersrust (Mokopane) & South Africa & Limpopo & -23.9368128 .73886 \\
31. Port Alfred & South Africa & Eastern Cape & -33.567826 .87988 \\
32. Port Elizabeth & South Africa & Eastern Cape & -33.970525 .60143 \\
33. Rustenburg Nature Reserve & South Africa & North west & -25.71727 .183 \\
34. Shilowa, Kruger National Park & South Africa & Limpopo & -23.4886231 .55872 \\
35. Silverton Ridge & South Africa & Gauteng & -25.7378728 .28667 \\
36. Buzzard Mountain, Soutpansberg & South Africa & Limpopo & -29.6871217 .98839 \\
37. Springbok & South Africa & Northern Cape & -23.0222429 .77105 \\
38. Steelpoort & South Africa & Mpumalanga & -24.6991330 .16197 \\
39. Uitenhage & South Africa & Eastern Cape & -33.7763525 .36435 \\
40. Vhembe Nature Reserve & South Africa & Limpopo & -22.2071229 .36348 \\
41. Volksrust & South Africa & Mpumalanga & -27.3779329 .75784 \\
42. Vredefort & South Africa & Free State & -26.968327 .29527 \\
43. Willem Pretorius Nature reserve & South Africa & Free State & -28.2834127 .21673 \\
\hline \hline
\end{tabular}


Supplementary Table S2

Molecular markers and primer details used in this study.

\begin{tabular}{llll}
\hline \multicolumn{1}{c}{ Locus } & $\begin{array}{r}\text { Primer } \\
\text { name }\end{array}$ & \multicolumn{1}{c}{ Primer Sequences (5'-3') } & \multicolumn{1}{c}{ Primer Source } \\
\hline \multirow{2}{*}{ Cytochrome $b(\mathrm{Cyt} b)$} & L14724 (P) & AGACATGAAAAATCACCGTTG & Irwin et al., 1991 \\
& H15915 (P) & CGTTAGTGGCTTACAAGGC & \\
Acid Phosphatase intron 5 (AP5) & Ap5 120F & AATGCCCCATTCCACAC & DeBry et al., 2001 \\
& Ap5 564R & GCAGAGACGTTGCCAAG & \\
& Ap5 139F & CCCGGGAAATGGCCAATG & Pääbo and Wilson, 1988; Irwin et \\
& Ap5 545R & GATCATGGTTTCCAGCAGCAG & al., 1991; Matthee et al., 2001, \\
& Prkc1F & GGGTAATAGGAAGAGGAAGTT & 2007
\end{tabular}




\section{Supplementary Table S3}

Polymorphic microsatellite loci utilised for $P$. c capensis which were previously developed in $P$. $c$. johnstoni. Description of the primer sequences, repeat motifs, expected size ranges (bp) and annealing temperatures; $\mathrm{MgCl}_{2}$ concentrations (not shown) varied between (1.5 mM-3 mM).

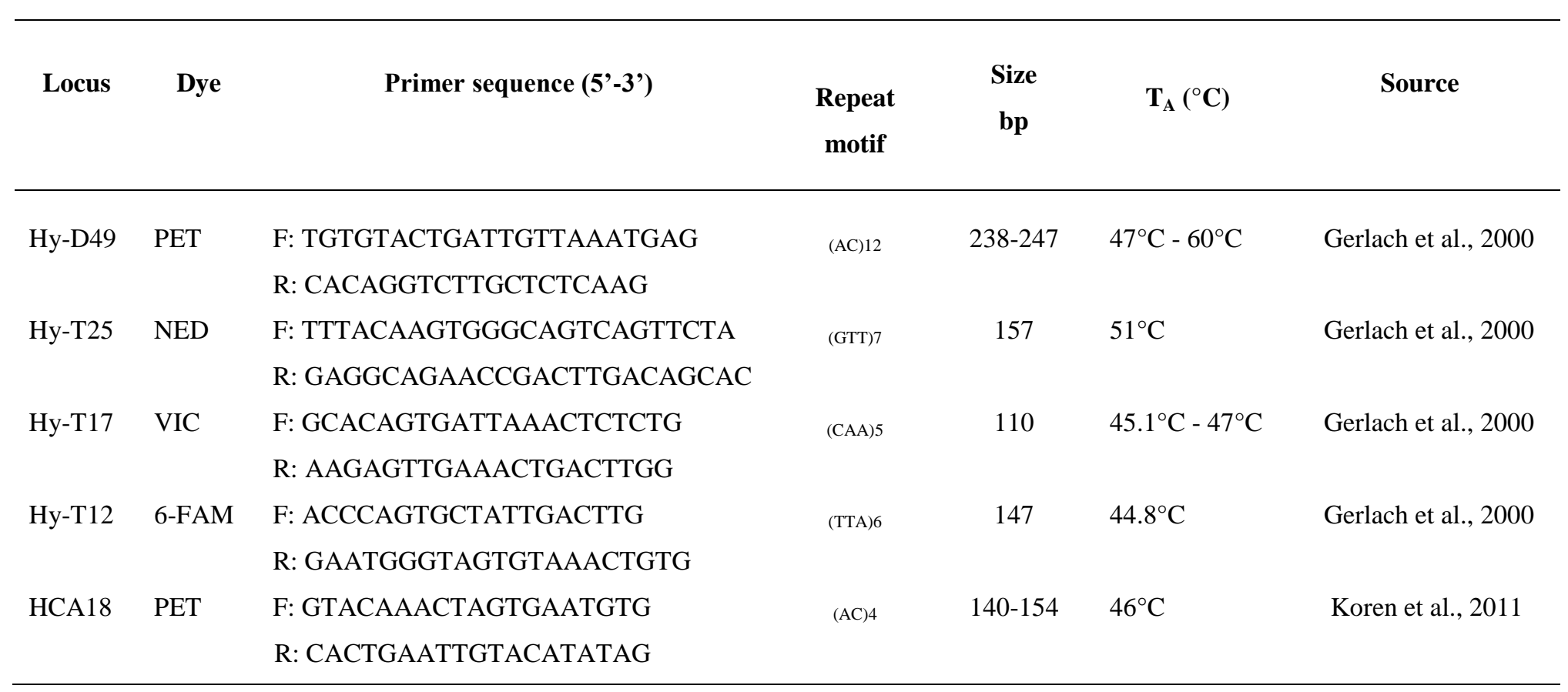




\section{Supplementary Table S4}

Sample details used in this study with corresponding localities, haplotype and GenBank accession numbers for each gene region. Dashes (-) represent unsequenced loci.

\begin{tabular}{|c|c|c|c|c|c|c|c|}
\hline \multirow[t]{2}{*}{ Sample Id } & \multirow[t]{2}{*}{ Locality } & \multicolumn{2}{|c|}{ Cyt-b } & \multicolumn{2}{|c|}{ Ap5 } & \multicolumn{2}{|c|}{ Prkc1 } \\
\hline & & $\begin{array}{l}\text { Haplotype } \\
\text { number }\end{array}$ & GenBank & $\begin{array}{l}\text { Haplotype } \\
\text { number }\end{array}$ & GenBank & $\begin{array}{l}\text { Haplotype } \\
\text { number }\end{array}$ & GenBank \\
\hline Pc11.7(P) & Mooketsi & Chb11 & KY062803 & Cha15 & KY441680 & Chp12 & KY231943 \\
\hline Pc15.1(P) & Soutpansberg (buzzard mountain) & Chb11 & KY062810 & - & & - & \\
\hline Vhe1 & Vhembe & Chb11 & KY062841 & Cha05 & KY441704 & - & \\
\hline Vhe3 & Vhembe & Chb11 & KY062842 & Cha05 & KY441705 & - & \\
\hline Pc11.5(P) & Mooketsi & Chb12 & KY062802 & Cha01 & KY441679 & - & \\
\hline Pc11.4(P) & Mooketsi & Chb13 & KY062801 & Cha05 & KY441678 & - & \\
\hline Am19 & Hoedspruit & Chb09 & KY062835 & Cha01 & KY441696 & Chp04 & KY231954 \\
\hline Pc16.1(P) & Blouberg & Chb06 & KY062811 & Cha01 & KY441685 & - & \\
\hline Pc22.1(P) & Mica & Chb07 & KY062820 & - & & - & \\
\hline $\mathrm{Pc} 22.2(\mathrm{P})$ & Mica & Chb07 & KY062821 & - & & - & \\
\hline Pc17.3(P) & Blackhills (gravellotte) & $\mathrm{CHb03}$ & KY062814 & Cha03 & KY441687 & - & \\
\hline Pc17.4(P) & Blackhills (gravellotte) & $\mathrm{CHb03}$ & KY062815 & Cha13 & KY441688 & - & \\
\hline Vhe4 & Vhembe & $\mathrm{CHb04}$ & KY062843 & Cha01 & KY441706 & - & \\
\hline Vhe5 & Vhembe & - & & Cha01 & KY441707 & - & \\
\hline Vhe9R & Vhembe & $\mathrm{CHb} 05$ & KY062844 & Cha05 & KY441708 & - & \\
\hline Vhe10 & Vhembe & $\mathrm{CHb05}$ & KY062845 & Cha05 & KY441709 & Chp13 & KY231962 \\
\hline Pc25.3(P) & Vredefort & $\mathrm{CHb01}$ & KY062827 & - & & - & \\
\hline APc25.4 & Vredefort & $\mathrm{CHb01}$ & KY062828 & Cha05 & KY441695 & Chp03 & KY231948 \\
\hline Pc25.5(P) & Vredefort & $\mathrm{CHb01}$ & KY062829 & - & & - & \\
\hline Pc26.1(P) & Heidelberg & $\mathrm{CHb01}$ & KY062830 & - & & - & \\
\hline Pc26.2(P) & Heidelberg & $\mathrm{CHb01}$ & KY062831 & - & & - & \\
\hline
\end{tabular}




\begin{tabular}{|c|c|c|c|c|c|c|c|}
\hline PcPs1.2 & Silverton Ridge & $\mathrm{CHb01}$ & KY062838 & - & & Chp07 & KY231957 \\
\hline PcPs1 & Silverton Ridge & $\mathrm{CHb01}$ & KY062839 & - & & - & \\
\hline PcPs2 & Silverton Ridge & $\mathrm{CHb01}$ & KY062840 & - & & - & \\
\hline Pc19.1(P) & Middelburg & $\mathrm{CHb02}$ & KY062816 & Cha01 & KY441690 & - & \\
\hline Pc19.3(P) & Middelburg & $\mathrm{CHb02}$ & KY062817 & - & & - & \\
\hline Pc19.5(P) & Middelburg & $\mathrm{CHb02}$ & KY062819 & - & & - & \\
\hline Pc22.3(P) & Mica & $\mathrm{CHb02}$ & KY062822 & Cha05 & KY441691 & - & \\
\hline Pc12.1(P) & Kguger N & $\mathrm{CHb} 15$ & KY062804 & - & & - & \\
\hline Pc12.4(P) & Kruger N & $\mathrm{CHb} 10$ & KY062807 & Cha05 & KY441681 & - & \\
\hline Pc11.2(P) & Mooketsi & CHb17 & KY062799 & - & & - & \\
\hline Pc11.3(P) & Mooketsi & CHb16 & KY062800 & Cha05 & KY441677 & - & \\
\hline Pc23.2(A) & Kruger Lebombo mountains & $\mathrm{CHb} 16$ & KY062825 & Cha05 & KY441692 & Chp08 & KY231945 \\
\hline $\mathrm{Pc} 23.3(\mathrm{P})$ & Kruger Lebombo mountains & CHb16 & KY062826 & - & & - & \\
\hline Pc12.2(P) & Kruger N & CHb18 & KY062805 & - & & - & \\
\hline Pc19.4(P) & Middelburg & $\mathrm{CHb} 18$ & KY062818 & - & & - & \\
\hline Pc22.4 & Mica & $\mathrm{CHb} 18$ & KY062823 & - & & - & \\
\hline Pc22.5(P) & Mica & $\mathrm{CHb} 18$ & KY062824 & - & & - & \\
\hline PcL1 & Lissataba & CHb19 & KY062836 & - & & - & \\
\hline Pc14.1(P) & Potgietersrus (mokopane) & $\mathrm{CHb} 20$ & KY062808 & Cha08 & KY441683 & - & \\
\hline Pc14.2(P) & Potgietersrus (mokopane) & $\mathrm{CHb} 20$ & KY062809 & Cha01 & KY441684 & - & \\
\hline Pc13.1(P) & Marken & - & & Cha05 & KY441682 & - & \\
\hline Pc6.2 & Springbok & $\mathrm{CHb} 21$ & KY062854 & - & & - & \\
\hline Pc6.3 & Springbok & $\mathrm{CHb} 21$ & KY062855 & - & & - & \\
\hline PcPa1 & Port Alfred & $\mathrm{CHb} 22$ & KY062847 & - & & - & \\
\hline PcUi1 & Uitenhage & $\mathrm{CHb} 22$ & KY062848 & Cha05 & KY441700 & \begin{tabular}{|l|} 
Chp01 \\
\end{tabular} & KY231958 \\
\hline PcUi2 & Uitenhage & $\mathrm{CHb} 22$ & KY062849 & - & & Chp18 & KY231959 \\
\hline Pc6.1 & Springbok & $\mathrm{CHb} 44$ & KY062853 & Cha05 & KY441668 & Chp19 & KY231937 \\
\hline Pc10.11 & Kuruman & $\mathrm{CHb} 43$ & KY062878 & Cha01 & KY441675 & - & \\
\hline Pc4.1 & Pilgrims Rest & $\mathrm{CHb} 23$ & KY062850 & Cha14 & KY441665 & \begin{tabular}{|l|} 
Chp19 \\
\end{tabular} & KY231935 \\
\hline Pc4.4 & Pilgrims Rest & $\mathrm{CHb} 23$ & KY062851 & Cha05 & KY441666 & \begin{tabular}{|l|} 
Chp19 \\
\end{tabular} & KY231936 \\
\hline Pc27.1(P) & Ermelo & $\mathrm{CHb} 24$ & KY062887 & - & & - & \\
\hline PPc27.2 & Ermelo & $\mathrm{CHb} 24$ & KY062888 & - & & \begin{tabular}{|l|} 
Chp19 \\
\end{tabular} & KY231949 \\
\hline Pc20.1.2 & Lydenburg & $\mathrm{CHb} 25$ & KY062884 & - & & - & \\
\hline Pc24.1(P) & Blyde River & $\mathrm{CHb} 25$ & KY062885 & Cha01 & KY441693 & Chp19 & KY231946 \\
\hline Pc24.2(A) & Blyde River & $\mathrm{CHb} 25$ & KY062886 & Cha09 & KY441694 & \begin{tabular}{|l|} 
Chp01 \\
\end{tabular} & KY231947 \\
\hline Pc12.6(P) & Kruger Maqili & $\mathrm{CHb} 26$ & KY062879 & - & & - & \\
\hline Pc18.1(P) & Volksrust & $\mathrm{CHb} 42$ & KY062880 & Cha11 & KY441689 & - & \\
\hline
\end{tabular}




\begin{tabular}{|c|c|c|c|c|c|c|c|}
\hline Pc7.1 & Howick & $\mathrm{CHb} 28$ & KY062856 & - & & - & \\
\hline Pc7.7 & Howick & $\mathrm{CHb} 28$ & KY062862 & - & & - & \\
\hline Pc10.9.2 & Kuruman & $\mathrm{CHb} 28$ & KY062876 & - & & - & \\
\hline Pc27.3 & Ermelo & $\mathrm{CHb} 28$ & KY062889 & - & & - & \\
\hline Am20 & Willem Pretorius Nature Reserve & $\mathrm{CHb} 28$ & KY062891 & Cha05 & KY441697 & Chp10 & KY231955 \\
\hline Am22 & Koppies Dam Nature Reserve & $\mathrm{CHb} 28$ & KY062893 & - & & - & \\
\hline Pc18.2(P) & Volksrust & $\mathrm{CHb} 27$ & KY062881 & - & & - & \\
\hline Pc18.3(P) & Volksrust & $\mathrm{CHb} 27$ & KY062882 & - & & - & \\
\hline Pc18.4(P) & Volksrust & $\mathrm{CHb} 27$ & KY062883 & - & & - & \\
\hline Pc10.1(P) & Kuruman & CHb29 & KY062872 & - & & - & \\
\hline Pc10.3 & Kuruman & CHb29 & KY062873 & - & & - & \\
\hline Pc7.4.2(P) & Howick & CHb31 & KY062859 & - & & - & \\
\hline Pc7.5 & Howick & CHb31 & KY062860 & - & & - & \\
\hline Pc7.6 & Howick & CHb31 & KY062861 & - & & - & \\
\hline Pc9.1(P) & Bloemfontein & CHb32 & KY062864 & - & & - & \\
\hline Pc9.2(P) & Bloemfontein & CHb34 & KY062865 & Cha01 & KY441671 & - & \\
\hline Pc9.3(P) & Bloemfontein & CHb36 & KY062866 & - & & - & \\
\hline Pc9.4(P) & Bloemfontein & CHb36 & KY062867 & - & & - & \\
\hline Pc9.5(P) & Bloemfontein & CHb36 & KY062868 & - & & Chp11 & KY231940 \\
\hline Pc9.6(P) & Bloemfontein & CHb36 & KY062869 & Cha01 & KY441672 & - & \\
\hline Pc9.7(P) & Bloemfontein & CHb36 & KY062870 & Cha07 & KY441673 & - & \\
\hline Pc9.8(P) & Bloemfontein & CHb36 & KY062871 & - & & - & \\
\hline Am21 & Willem Pretorius Nature Reserve & CHb34 & KY062892 & - & & - & \\
\hline
\end{tabular}




\begin{tabular}{|c|c|c|c|c|c|c|c|}
\hline Pck5 & Koppies Dam Nature Reserve & $\mathrm{CHb} 35$ & KY062901 & - & & - & \\
\hline Pck6 & Koppies Dam Nature Reserve & CHb35 & KY062902 & Cha05 & KY441701 & - & \\
\hline $\mathrm{Mmk} / \mathrm{m} / 3375$ & Schurwepoort (koppies district) & $\mathrm{CHb} 33$ & KY062907 & - & & - & \\
\hline $\mathrm{Mmk} / \mathrm{m} / 6759$ & Kimberley & $\mathrm{CHb} 38$ & KY062906 & - & & - & \\
\hline Jac2 & Jacobsdal & CHb39 & KY062890 & Cha12 & KY441698 & - & \\
\hline Pc8.1 & East London & $\mathrm{CHb} 40$ & KY062863 & Cha05 & KY441670 & Chp01 & KY231939 \\
\hline Pcmr1 & Morgenson & - & & - & & Chp15 & KY231950 \\
\hline Pcmr2 & Morgenson & - & & Cha10 & KY441699 & Chp19 & KY231951 \\
\hline Am17 & Steelport & - & & - & & Chp09 & KY231953 \\
\hline Gbr665 & Namibia & $\mathrm{CHb} 45$ & KY062908 & - & & Chp21 & KY231963 \\
\hline P. c. syriaca & Haifa, Israel & & AF045131 & & & & \\
\hline
\end{tabular}




\section{Supplementary Table S5}

The total number samples $N$, total numbers of alleles $(N \mathrm{a})$, Allelic richness $\left(A_{\mathrm{R}}\right)$ and the average Observed heterozygosity $\left(H_{\mathrm{O}}\right)$, Expected heterozygosity $\left(H_{\mathrm{E}}\right)$ and inbreeding coefficient $\left(F_{\mathrm{IS}}\right)$ (Weir \& Cockerham, 1984) over all microsatellite markers in the lineage partitioned data set (northern \& southern lineages, respectively) of Procavia capensis. Deviations from HWE are indicated in bold.

\begin{tabular}{|c|c|c|c|c|c|c|c|c|c|c|c|c|}
\hline \multirow[t]{2}{*}{ Locus } & \multicolumn{2}{|c|}{$N$} & \multicolumn{2}{|c|}{$\begin{array}{c}N a \\
\text { (total) }\end{array}$} & \multicolumn{2}{|c|}{$A_{\mathrm{r}}$} & \multicolumn{2}{|c|}{$\begin{array}{c}\boldsymbol{H}_{\mathrm{O}} \\
(\text { ave })\end{array}$} & \multicolumn{2}{|c|}{$\begin{array}{c}\boldsymbol{H}_{\mathrm{E}} \\
\text { (ave) }\end{array}$} & \multicolumn{2}{|c|}{$\begin{array}{c}F_{I S} \\
\text { (ave) }\end{array}$} \\
\hline & $\begin{array}{l}\text { Pop } \\
1\end{array}$ & $\begin{array}{l}\text { Pop } \\
2\end{array}$ & $\begin{array}{l}\text { Pop } \\
1\end{array}$ & $\begin{array}{l}\text { Pop } \\
2\end{array}$ & $\begin{array}{l}\text { Pop } \\
1\end{array}$ & $\begin{array}{l}\text { Pop } \\
2\end{array}$ & $\begin{array}{l}\text { Pop } \\
1\end{array}$ & $\begin{array}{l}\text { Pop } \\
2\end{array}$ & $\begin{array}{l}\text { Pop } \\
1\end{array}$ & $\begin{array}{l}\text { Pop } \\
2\end{array}$ & $\begin{array}{l}\text { Pop } \\
1\end{array}$ & $\begin{array}{l}\text { Pop } \\
2\end{array}$ \\
\hline $\begin{array}{l}\text { Hy-D49 } \\
\text { HCA18 } \\
\text { Hy-T25 } \\
\text { Hy-T17 } \\
\text { Hy-T12 }\end{array}$ & $\begin{array}{l}36 \\
45 \\
28 \\
35 \\
31\end{array}$ & $\begin{array}{l}40 \\
57 \\
41 \\
49 \\
48\end{array}$ & $\begin{array}{l}10 \\
10 \\
6 \\
6 \\
7\end{array}$ & $\begin{array}{l}14 \\
9 \\
4 \\
7 \\
7\end{array}$ & $\begin{array}{l}9.5 \\
10.2 \\
6.0 \\
5.9 \\
6.8\end{array}$ & $\begin{array}{l}13.5 \\
8.7 \\
3.9 \\
7.3 \\
6.6\end{array}$ & $\begin{array}{l}0.69 \\
0.84 \\
0.18 \\
0.29 \\
0.26\end{array}$ & $\begin{array}{l}0.83 \\
0.88 \\
0.27 \\
0.47 \\
0.56\end{array}$ & $\begin{array}{l}0.84 \\
0.81 \\
0.34 \\
0.43 \\
0.54\end{array}$ & $\begin{array}{l}0.85 \\
0.80 \\
0.28 \\
0.70 \\
0.70\end{array}$ & $\begin{array}{l}\mathbf{0 . 1 9} * \\
-\mathbf{0 . 0 3} * * \\
0.50 * * \\
0.35 * \\
0.53 * * *\end{array}$ & $\begin{array}{l}\mathbf{0 . 0 5} * \\
\mathbf{- 0 . 0 9}^{*} * * \\
0.06 \\
\mathbf{0 . 3 4} * * * \\
\mathbf{0 . 2 1} * * *\end{array}$ \\
\hline & & & & 11 & 8.0 & 9.2 & 0.45 & 0.60 & 0.60 & 0.67 & 0.25 & 0.11 \\
\hline
\end{tabular}

$* P$-value $<0.05, * * P$-value $<0.01$ and $* * * P$-value $<0.001$. After Bonferroni (correction at $\mathrm{P}<0.05)$. 


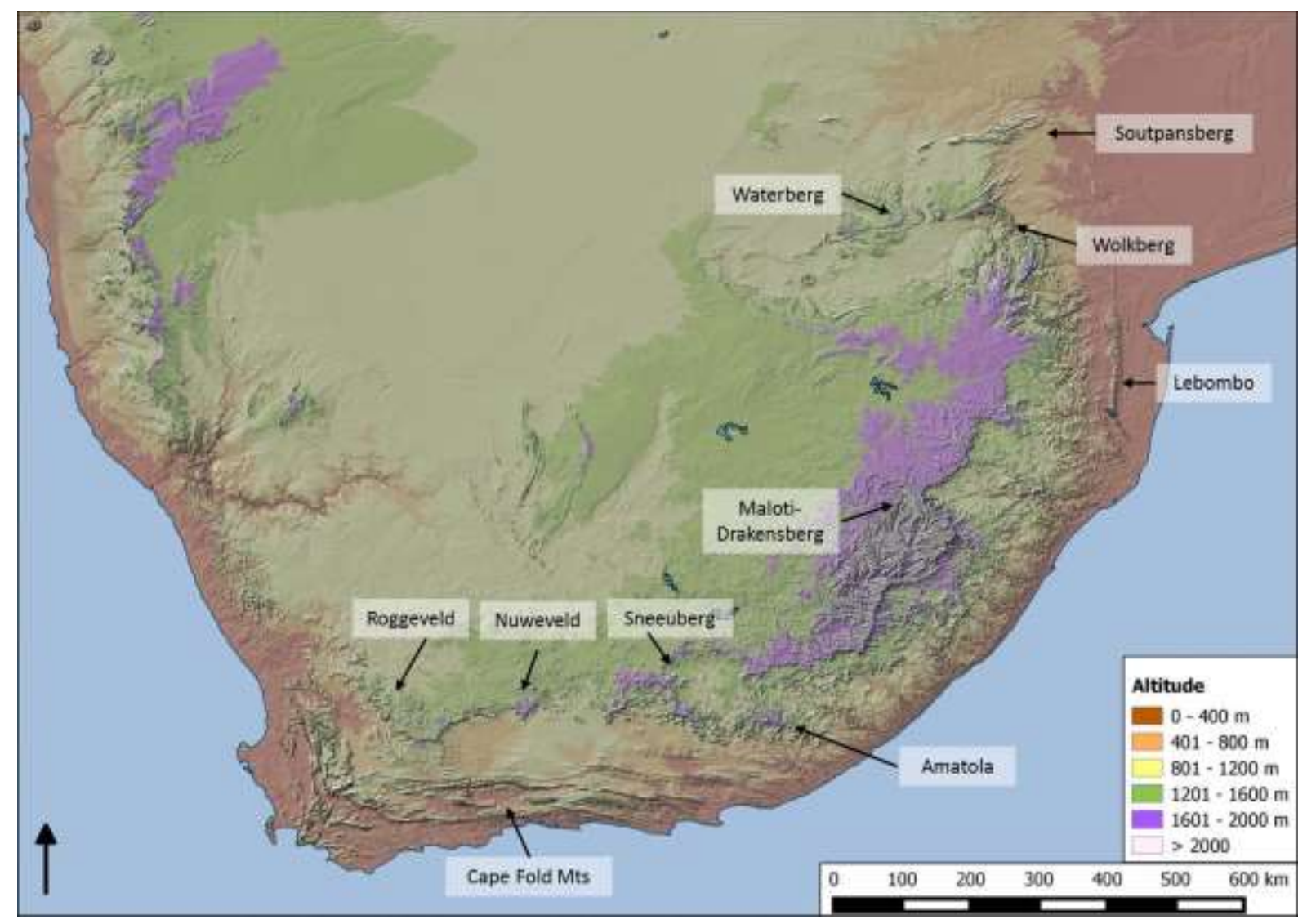

Supplementary Fig. S1. Map of southern Africa with information on the Great Escarpment, its associated mountain ranges and their corresponding elevations (colour coded key of the legend on the right hand side). 

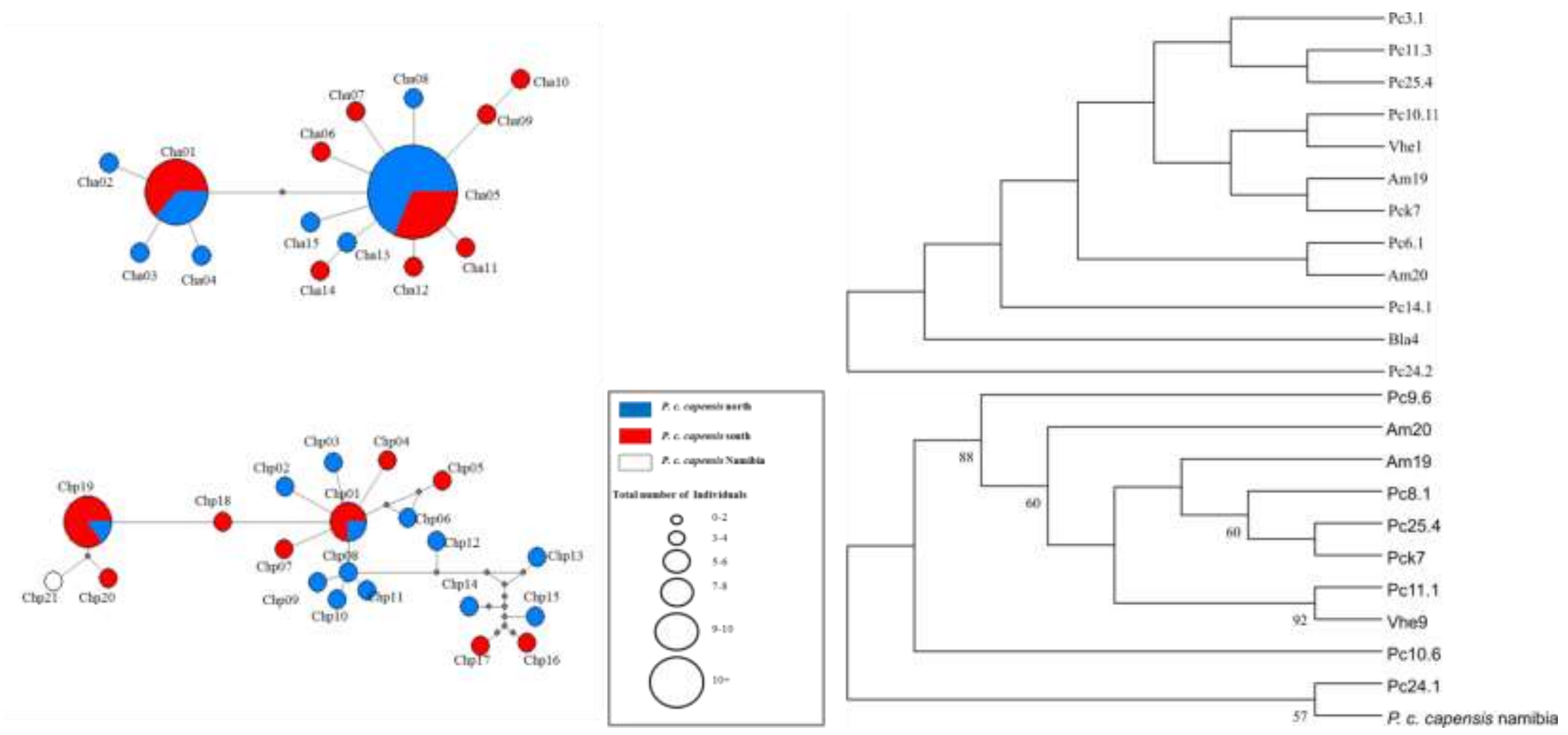

Supplementary Fig. S2. Nuclear intron networks (left) and ML trees (right) representing AP5 (top) and Prkc1 (bottom), respectively. 
A
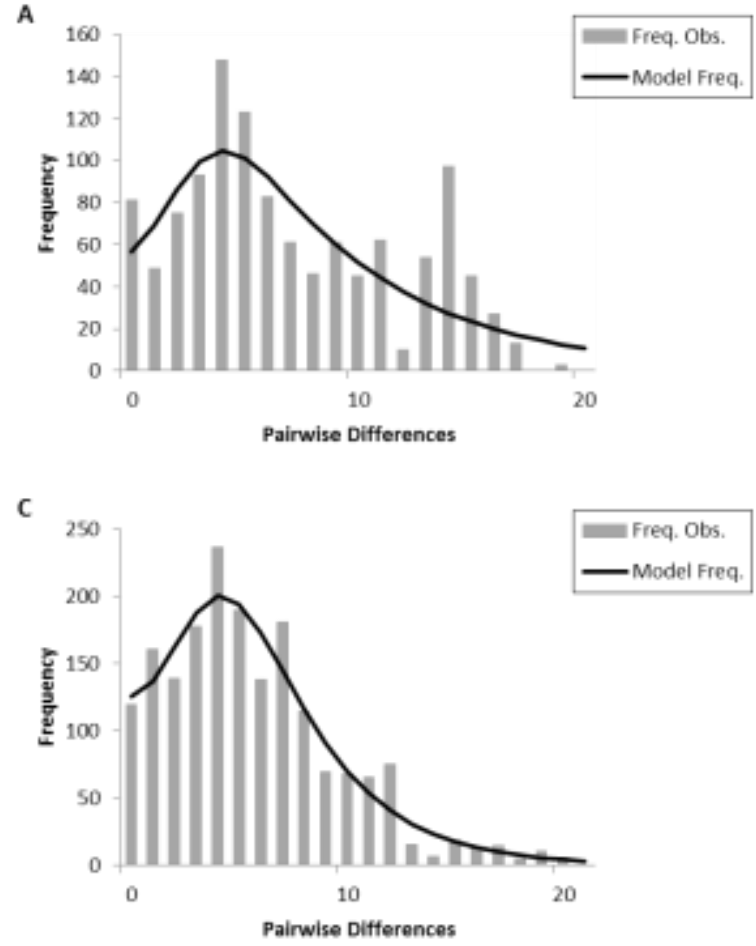

B

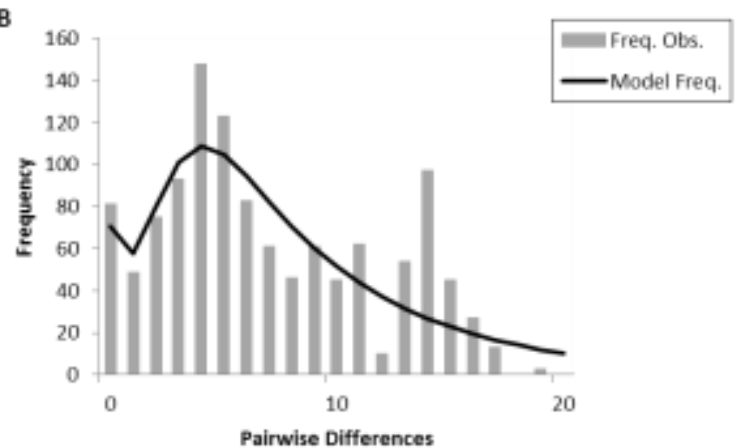

D

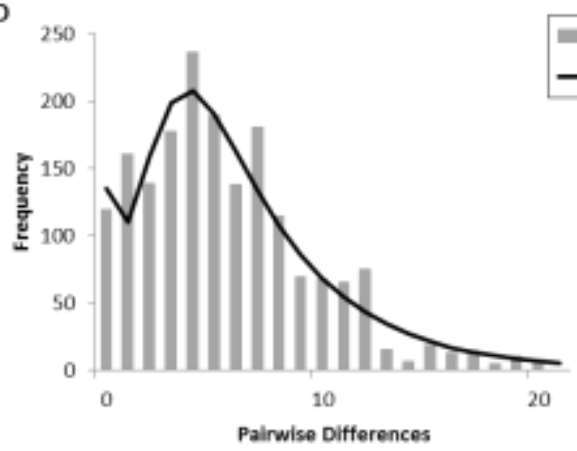

Supplementary Fig. S3. Mismatch distributions for the northern (A, B) and southern (C, D) mtDNA lineages. In $\mathrm{A}$ and $\mathrm{C}$, observed pairwise differences are compared against the expected distribution under the sudden expansion model $(P=0.012, P=0.57$ and $P=0.90$, respectively). In $\mathrm{B}$ and $\mathrm{D}$ these are compared against the spatial expansion model $(P=0.21, P=0.69$ and $P=0.89$, respectively). 

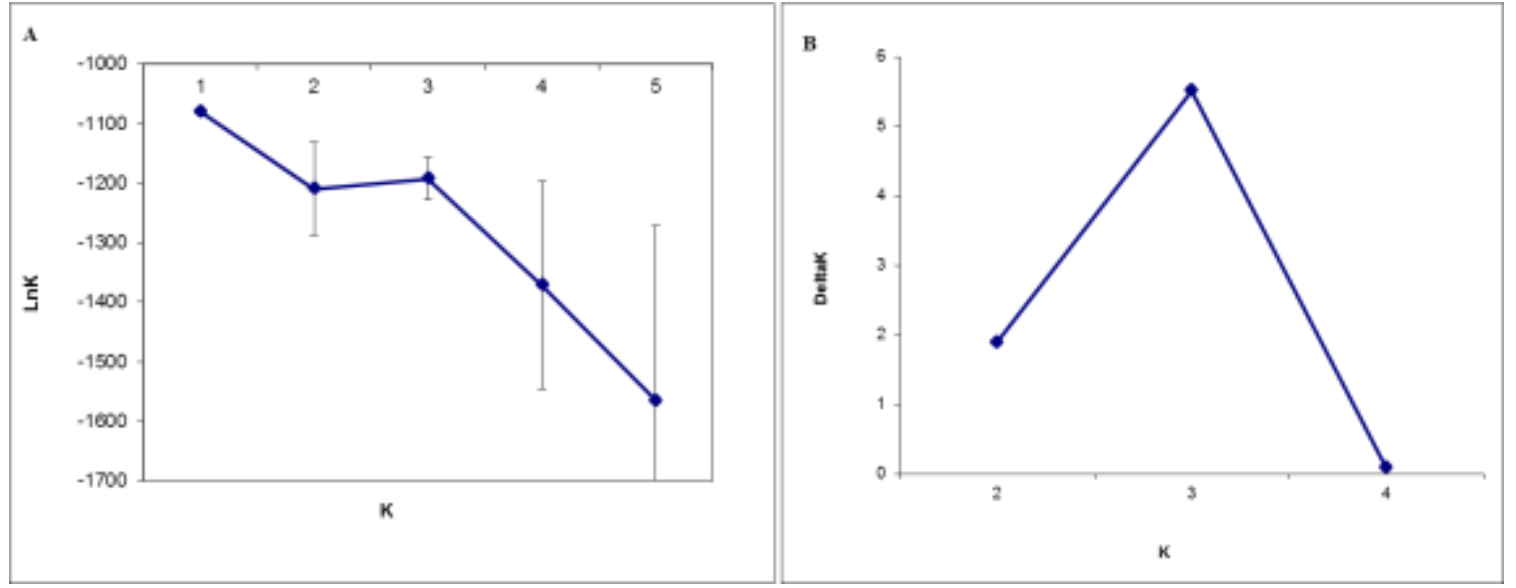

Supplementary Fig. S4. Inference of the likely number of genetic clusters $(K)$ in Structure Harvester based on microsatellite genotypes of Procavia capensis capensis. Locus HyT-17 was excluded due to the presence of null alleles. Graph (A) represents the log probability of each $K$, with standard deviations based on 20 iterations for each value of $K$, and (B) represents the $a d$ hoc statistic $\Delta K$ for each value of $K$. 


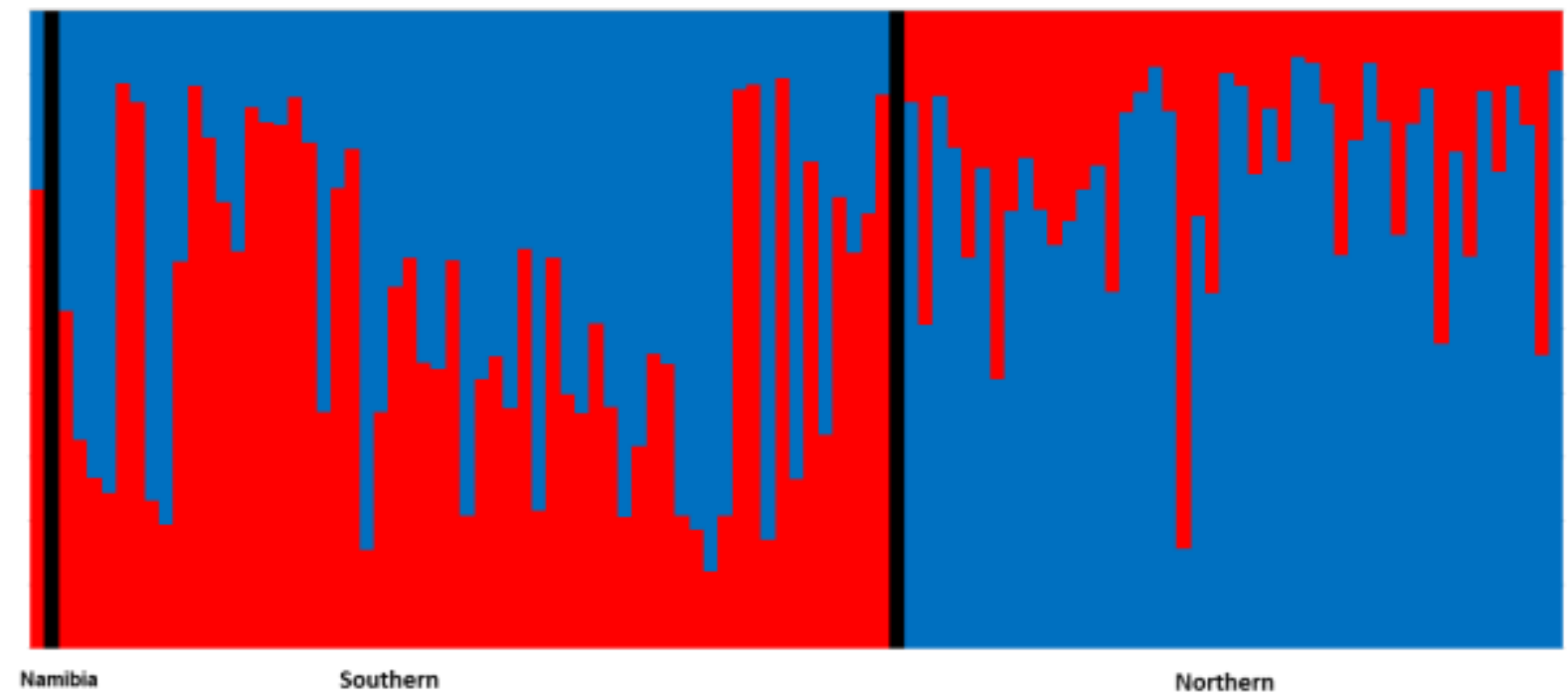

Supplementary Fig. S5. Structure plot (Pritchard et al., 2000) for $K=2$ genetic clusters (indicated with red and blue) based on microsatellite loci in Procavia capensis capensis. Each vertical bar represents the individual membership $(q)$ to $K$-clusters. Location was not used as prior but the regions where the individuals originated are indicated (solid black bars separate the individual from Namibia from the southern and northern South African lineages). 


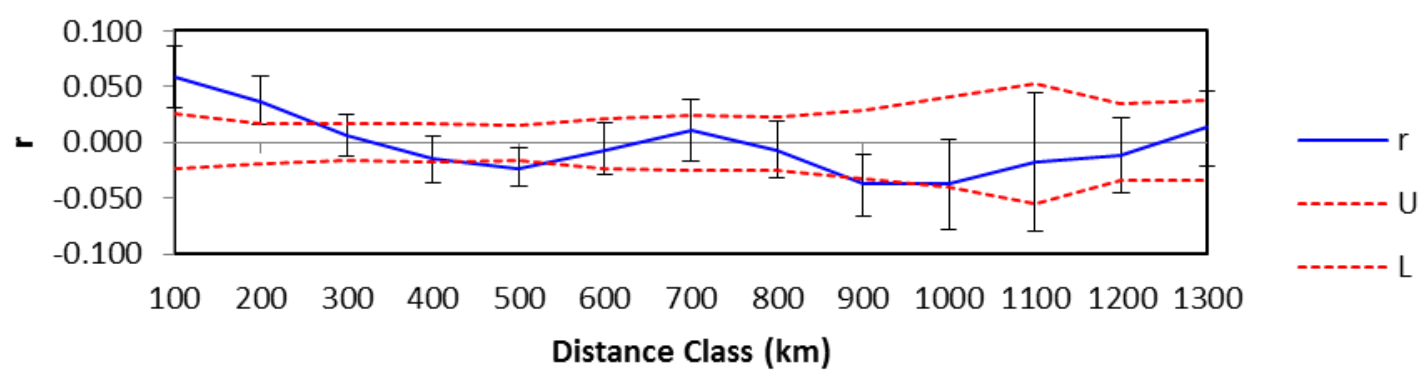

B Results of Spatial Structure Analysis from the combined hyrax data

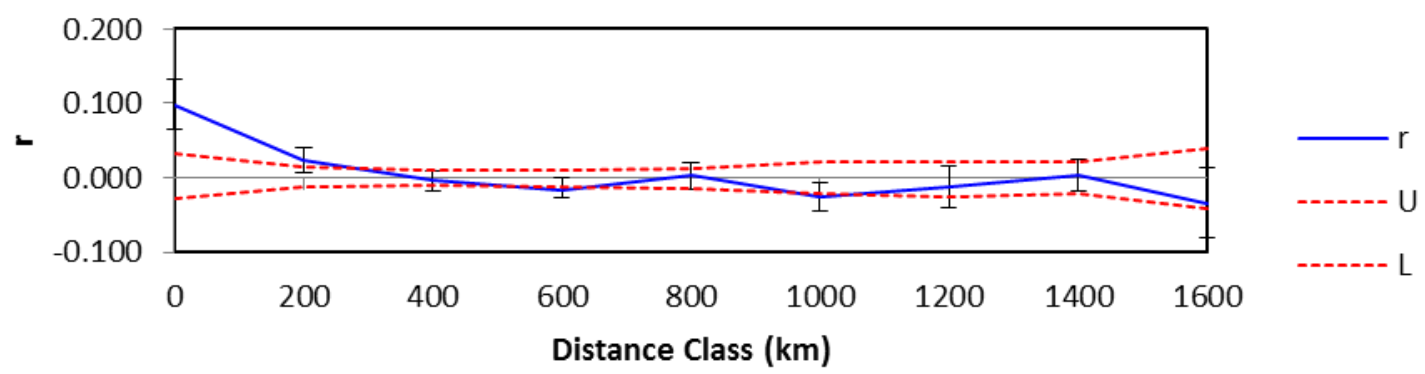

Supplementary Fig. S6. Spatial autocorrelation correlograms in Procavia capensis capensis for the microsatellite data (A) and the combined (mtDNA \& five microsatellite loci) datasets (B). The analysis considered geographic distances with even distance class of $50 \mathrm{~km}$. Dashed lines encompass the 95\% confidence interval of the null hypothesis, and each point represents the autocorrelation coefficient (rc). 